\title{
Chapter 20 \\ Thermodynamic-Mechanical Modeling of Metastable High Alloy Austenitic CrMnNi Steels
}

\author{
Michael Hauser, Marco Wendler, Javad Mola, Olga Fabrichnaya, \\ Olena Volkova and Andreas Weiß
}

\begin{abstract}
The deformation-induced formation of $\alpha^{\prime}$-martensite was investigated by tensile testing of a X $5 \mathrm{CrNi} 18-10$ wrought austenitic steel and $\mathrm{X} 3 \mathrm{CrMnNi} 16-7-3 / 6 / 9$ (Ni contents of 3, 6, and 9 mass\%) as well as X15CrNiMnN19-4-3 cast austenitic steels at temperatures between -80 and $400{ }^{\circ} \mathrm{C}$. The results were presented in the form of Stress-Temperature-Transformation (STT) and Deformation-TemperatureTransformation (DTT) diagrams. The diagrams laid foundations for the development of a method for the quantitative determination of strength and elongation contributions by means of induced and often overlapping deformation processes in the austenite. The summation of such contributions yielded the tensile strength and the uniform elongation of the steel. In order to determine the critical Gibbs free energy for the formation of martensite at temperatures between $M_{\mathrm{s}}$ and $M_{\mathrm{d}}$, the chemical and mechanical contributions to deformation-induced martensite formation were determined by CALPHAD method using Thermo-Calc software. The mechanical contribution was estimated by determining the triggering stress for the formation of martensite using an in situ magnetic measurement device. This was done using the model proposed by Patel and Cohen. The magnitudes of shear strain $\left(\gamma_{0}\right)$ and dilatational strain $\left(\varepsilon_{0}\right)$, required for the calculations, were obtained based on the martensite crystallography theory of Wechsler-Lieberman-Read. The sum of the chemical and mechanical contributions yielded the critical driving force for the martensitic transformation.
\end{abstract}

M. Hauser $(\varangle) \cdot$ M. Wendler $\cdot$ O. Volkova $\cdot$ A. Weiß

Institute of Iron and Steel Technology, Technische Universität Bergakademie Freiberg, Leipziger Str. 34, 09599 Freiberg, Germany

e-mail: michael.hauser@iest.tu-freiberg.de

J. Mola

Material Design and Structural Integrity Lab, Osnabrück University of Applied Sciences, 49076 Osnabrück, Germany

O. Fabrichnaya

Institute of Materials Science, Technische Universität Bergakademie Freiberg, Gustav-Zeuner-Str. 5, Freiberg, Germany 


\subsection{Introduction}

Depending on the chemical composition and deformation temperature, deformation mechanisms such as dislocations cell formation, mechanical twinning, and martensitic transformation may occur in the austenite phase of austenitic high-alloy steels [1-12]. The martensite commonly forms at intersections of glide bands in the austenite. At low temperatures where martensite formation is enabled, glide bands may consist of stacking fault bundles, $\varepsilon$ martensite, and mechanical twins [13, 14].

In austenitic steels exhibiting the transformation-induced plasticity (TRIP) effect, the knowledge of the minimum driving force necessary for the martensite formation is of primary importance. The concept of defining a critical driving force for the martensite nucleation was first put forward by Cohen and coworkers $[15,16]$ and has been extended by Ghosh and Olson to include the effect of alloying elements [17]. This concept enables the thermodynamic modeling of metastable austenitic steels and can be used as a powerful tool to design new engineering materials [18-23]. The accuracy of such calculations will then depend on the reliability of the thermodynamic data. The thermodynamic database is particularly trustworthy in the chemical composition range where it has been calibrated by experimental data $[24,25]$.

The focus of the present work is the thermodynamic-mechanical modeling of metastable high alloy austenitic CrMnNi steels. To collect the experimental results needed for modeling, several steels were investigated. With the aid of thermodynamic data and flow curve analysis, it is possible to describe the dependence of mechanical properties on deformation mechanisms and phase transformation.

\subsection{Experimental Methods}

The chemical composition of the investigated steels are shown in Table 20.1. The steel X5CrNi18-10 was produced from BGH Edelstahl Freital GmbH, Germany. The steel $\mathrm{X} 3 \mathrm{CrMnNi16}-7-6$ was molten in an induction furnace and cast into a sand mould by ACTech GmbH, Freiberg, Germany. The steels X3CrMnNi16-7-3/9 were melted in a vacuum induction furnace and cast into a water-cooled copper mould. The steel X15CrNiMnN19-4-3 was melted in the vacuum induction furnace under a

Table 20.1 Chemical composition of the investigated cast steels in mass $\%$

\begin{tabular}{l|l|l|l|l|l|l|l}
\hline Alloy & $\mathrm{C}$ & $\mathrm{N}$ & $\mathrm{Cr}$ & $\mathrm{Mn}$ & $\mathrm{Ni}$ & $\mathrm{Si}$ & $\mathrm{Fe}$ \\
\hline X5CrNi18-10 & 0.045 & 0.018 & 17.2 & 1.82 & 8.8 & 0.5 & bal. \\
\hline X3CrMnNi16-7-3 & 0.028 & 0.009 & 16.4 & 7.0 & 3.1 & 1.0 & bal. \\
\hline X3CrMnNi16-7-6 & 0.034 & 0.033 & 15.5 & 6.1 & 6.1 & 1.0 & bal. \\
\hline X3CrMnNi16-7-9 & 0.031 & 0.013 & 16.4 & 6.9 & 9.0 & 1.1 & bal. \\
\hline X15CrNiMnN19-4-3 & 0.154 & 0.167 & 18.7 & 2.9 & 4.2 & 0.5 & bal. \\
\hline
\end{tabular}


nitrogen partial pressure of 450 mbar followed by casting into a water-cooled copper mould with a dimension of $230 \times 35 \times 95 \mathrm{~mm}^{3}$. To avoid pore formation in the ingot, the nitrogen partial pressure was raised to 1500 mbar during casting.

To ensure the absence of machining-induced martensite near the surface of tensile specimens, solution heat treatments were performed after machining of tensile specimens. The solution heat treatment aimed at the dissolution of carbides and nitrides likely existing in the as-cast microstructure The solution heat treatment consisted of holding the $\mathrm{X} 5 \mathrm{CrNi} 18-10$ steel at $1050{ }^{\circ} \mathrm{C}$ for $60 \mathrm{~min}$, the $\mathrm{X} 3 \mathrm{CrMnNi} 16-7-3 / 6 / 9$ steels at $1050{ }^{\circ} \mathrm{C}$ for $30 \mathrm{~min}$ and the $\mathrm{X} 15 \mathrm{CrNiMnN} 19-4-3$ steel at $1150{ }^{\circ} \mathrm{C}$ for $30 \mathrm{~min}$ under an argon atmosphere.

Using a Zwick 1476-type universal testing machine, tensile specimens were tested at a constant crosshead displacement speed with an initial strain rate of $4 \times 10^{-4}$ $\mathrm{s}^{-1}$. With the aid of a thermal chamber which surrounded the tensile specimen and the specimen fixtures, different temperatures in the range of -40 and $200{ }^{\circ} \mathrm{C}$ were adjusted. The tensile tests below $-40{ }^{\circ} \mathrm{C}$ were performed with the aid of an Instron S5982 universal testing machine.

An in situ magnetic measurement system was devised to determine the $\alpha^{\prime}$-martensite content formed during tensile tests [21]. The experimental setup is shown in Fig. 20.1. The magnetic measurement system consisted of two coils. The

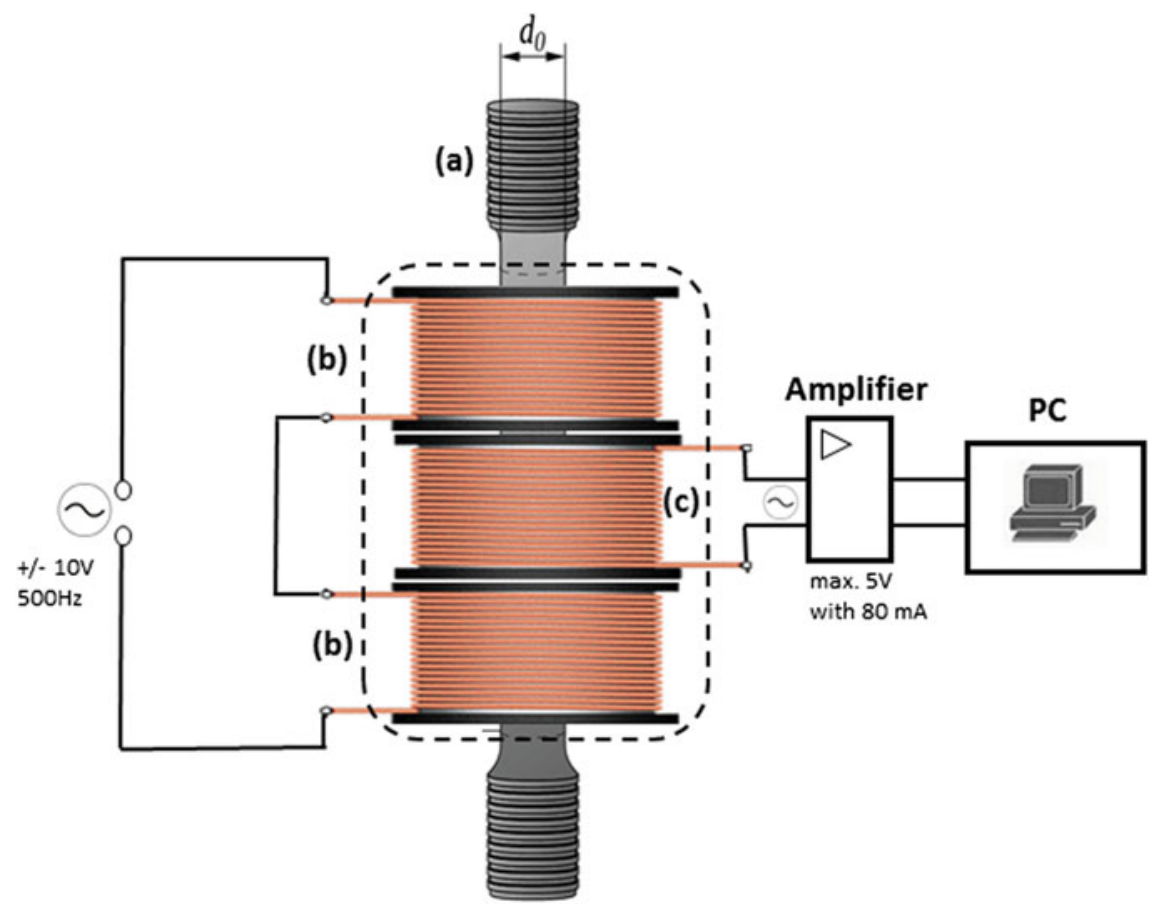

Fig. 20.1 Experimental setup showing tensile specimen and in situ magnetic measurement system with a tensile specimen, $\mathbf{b}$ first coil and $\mathbf{c}$ second coil 
first coil served to generate an electromagnetic field which magnetized the martensite phase as it formed during tensile loading. The magnetization of martensite phase in tensile specimens induced an electrical potential difference (voltage) in the second coil which was recorded. To avoid interactions between the magnetic field and the surrounding components in the thermal chamber, a relatively small current $(0.35 \mathrm{~A})$ was used. This led to a magnetic field strength of $15 \mathrm{kA} / \mathrm{m}$ in the gauge section of tensile specimens. To avoid thermal degradation of the polymer components of the magnetic coil, in situ magnetic measurements were only conducted in the temperature range -80 to $40{ }^{\circ} \mathrm{C}$.

The conversion of the voltage induced in the second coil to martensite fraction was done by a correlation procedure. The correlation procedure consisted of performing interrupted tensile tests followed by magnetic saturation measurements with an ex situ unit in order to quantify the $\alpha^{\prime}$-martensite fractions at the point of interruption. The procedure is described in more detail by Hauser et al. [21].

For the ex situ quantification of the ferromagnetic phase fraction in tensile specimens, a Metis MSAT-type magnetic saturation device equipped with a Lakeshore 480 fluxmeter was used. This equipment enabled the measurement of magnetic flux density after saturation magnetization of specimens cut from tensile specimens. The ferromagnetic phase fraction was calculated after an internal correction for the chemical composition. The correction took the influence of alloying elements on the magnetic moment of pure iron into account. The measurement accuracy with this method is within $\pm 1 \%$. Magnetic saturation measurements prior to tensile tests enabled the quantification of delta ferrite fractions retained after solution annealing. The delta ferrite fraction in solution annealed tensile specimens was also determined by quantitative metallography. These measurements closely reproduced the delta ferrite fraction based on ex situ magnetic saturation measurements. The microstructure was studied by means of electron channeling contrast imaging (ECCI) and electron backscatter diffraction (EBSD) techniques in a Zeiss LEO-1530 GEMINI-type field emission scanning electron microscope (FESEM). To calculate Gibbs free energies for the austenite (fcc) and ferrite (bcc) phases, the thermodynamic database developed by Franke et al. with the Thermo-Calc Software was used [26].

\subsection{Theoretical Background}

In metastable austenitic steels, martensite formation can occur spontaneously at temperatures below the martensite start $\left(M_{\mathrm{s}}\right)$ temperature and completes at the martensite finish $\left(M_{\mathrm{f}}\right)$ temperature. Martensite formation can also be triggered by deformation at temperatures up to $M_{\mathrm{d}}$ temperature, which leads to the so-called TransformationInduced Plasticity (TRIP)-effect. The austenite stability can be described as the sum of energy contributions which are beneficial to the martensitic phase transformation and those which hinder it. Whereas the mechanical energy ( $\left.W_{\text {mech }}\right)$, and at sufficiently low temperatures, the chemical driving force $\left(\Delta G_{\text {chem }}^{\gamma \rightarrow \alpha^{\prime}}\right)$ have a positive effect on the 
phase transformation, the non-chemical contribution $\left(\Delta G_{\mathrm{nc}}^{\gamma \rightarrow \alpha^{\prime}}\right)$ as defined in the following and the adiabatic heating $\left(Q_{\mathrm{ad}}\right)$ of the sample delay the phase transformation. When the total Gibbs free energy change ( $\Delta G_{\text {total }}$ ) is negative, thermodynamic driving force is available for the austenite to martensite transformation. Different energy contributions are included in (20.1) [18, 25, 27].

$$
\Delta G_{\text {total }}=\Delta G_{\text {chem }}^{\gamma \rightarrow \alpha^{\prime}}+\Delta G_{\mathrm{nc}}^{\gamma \rightarrow \alpha^{\prime}}+W_{\text {mech }}+Q_{\mathrm{ad}}
$$

While the adiabatic heating of the sample can be avoided by applying a low strain rate, the non-chemical energy contributions still need to be taken into account. The non-chemical energy contributions include the energy due to the lattice shear $\left(\Delta G_{\mathrm{sh}}\right)$, surface and interface energies $\left(\Delta G_{\text {sur }}\right)$ and elastic strain energy $\left(E^{\text {str }}\right)$, see in (20.2). All these energy contributions can be summed up to the critical driving force for the martensite formation $\left(\Delta G_{\text {crit }}^{\gamma \rightarrow \alpha^{\prime}}\right)[17,22,23,28]$.

$$
\Delta G_{\mathrm{nc}}=\Delta G_{\mathrm{sur}}+\Delta G_{\mathrm{sh}}+E^{\mathrm{str}} \triangleq \Delta G_{\mathrm{crit}}^{\gamma \rightarrow \alpha^{\prime}}
$$

In Fig. 20.2, the Gibbs free energy for martensite formation is shown as a function of temperature. The martensitic phase transformation can only occur at temperatures

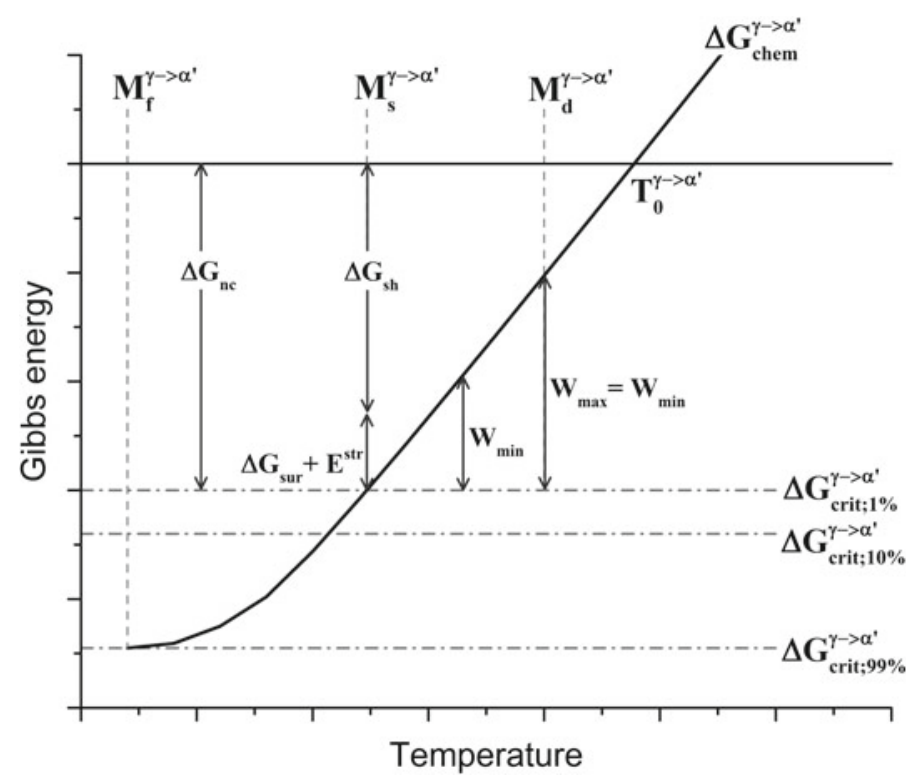

Fig. 20.2 Schematic representation of the temperature dependence of the chemical driving force for $\alpha^{\prime}$-martensite formation $\left(\Delta G_{\mathrm{chem}}^{\gamma \rightarrow \alpha^{\prime}}\right.$ ), minimum external mechanical work required to trigger the transformation $\left(W_{\min }\right)$, maximum applicable mechanical work $\left(W_{\max }\right)$, and critical driving forces for the formation of various martensite fractions $\left(\Delta G_{\text {crit }}^{\gamma \rightarrow \alpha^{\prime}}\right)$, and non-chemical contributions $\Delta G_{\mathrm{nc}}$ 
below $T_{0}^{\gamma \rightarrow \alpha^{\prime}}$, where the Gibbs free energies for austenite and ferrite of the same chemical composition are equal. Nevertheless, an additional energy contribution is needed to reach the critical driving force. At the $M_{\mathrm{s}}$ temperature and below, the chemical energy alone is high enough to trigger the martensitic phase transformation spontaneously. In the temperature range between $M_{\mathrm{s}}$ and $M_{\mathrm{d}}$ temperatures, on the other hand, the critical driving force can be reached by an additional energy contribution supplied by mechanical deformation. Therefore, the $M_{\mathrm{d}}$ temperature is the highest temperature where deformation-induced martensite formation can occur and thus the upper temperature limit to achieve the TRIP-effect with the maximum mechanical energy applicable to the material $\left(W_{\max }\right)$. During uniaxial tensile test, $W_{\max }$ denotes the maximum mechanical work applicable to austenite until the onset of localized deformation (necking). The applicable work determines the capacity of material to absorb external energy, thereby the amount of martensite that can be induced by deformation. Below the $M_{\mathrm{d}}$ temperature, one can define a minimal mechanical energy $\left(W_{\min }\right)$ which is needed to trigger the martensitic phase transformation. $W_{\min }$ reaches zero at $M_{\mathrm{s}}$ temperature. The larger the applied mechanical work with respect to $W_{\min }$, the larger the induced martensite fraction [18, 22, 23].

Looking at the spontaneous martensitic transformation from a thermodynamic point of view, three possible cases can arise at low temperatures (Fig. 20.3). Case

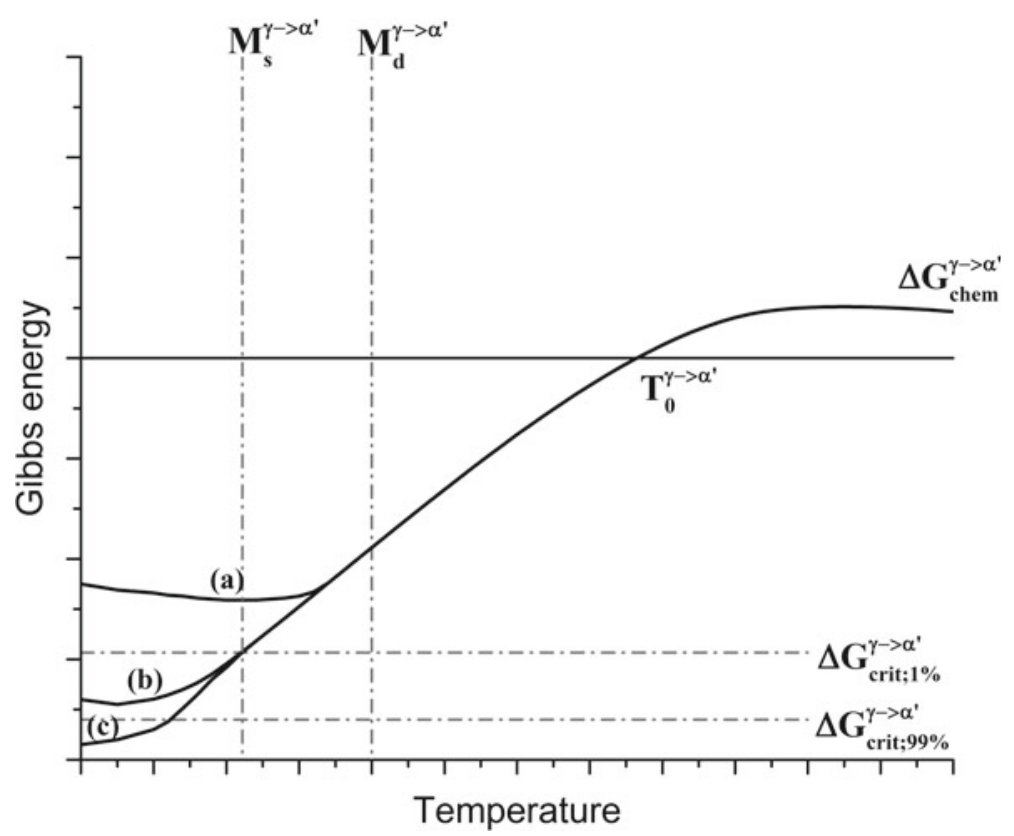

Fig. 20.3 Schematic representation of the temperature dependence of the chemical driving force for $\alpha^{\prime}$-martensite formation $\left(\Delta G_{\text {chem }}^{\gamma \rightarrow \alpha^{\prime}}\right.$ ), showing cases associated with the absence of spontaneous martensite (a), partial formation of spontaneous martensite (b), and full transformation to spontaneous martensite (c) 
(a) describes a metastable austenite without phase transformation. This case arises when the chemical driving force does not reach the critical driving force. Nevertheless, an additional mechanical energy might still enable the deformation-induced martensite formation. In case (b), as-quenched martensite formation occurs. Due to the increasing austenite stability at lower temperatures, caused by magnetic transition of austenite from paramagnetic to antiferromagnetic, the martensite formation might come to a standstill below the Néel temperature. In case (c), the martensitic phase transformation proceeds until completion because the chemical driving force is large enough to supply the critical driving force for the full transformation, namely $\Delta G_{\text {crit; } 99 \%}^{\gamma \rightarrow \alpha^{\prime}}[11,22,28]$.

The procedure proposed by Patel and Cohen for the calculation of the minimum and maximum mechanical work needed to induce martensite is discussed in detail in the following [29]. When loading metastable austenite, the applied stress leads to unequal resolved shear stresses on glide systems in the austenite, thereby favoring the selective formation of martensite variants [11]. For transformations associated with pure shear, the habit plane for the transformation will make an angle of $45^{\circ}$ with respect to the external loading direction. However, due to the dilatational component associated with martensitic transformation [29, 30], the habit plane for the deformation-induced martensite formation does not necessarily make an angle of $45^{\circ}$ with the tensile loading direction [23].

The mechanical work $W_{\text {mech }}$ which can trigger the martensite formation during the tensile test depends on the molar volume $\left(V_{\mathrm{m}}\right)$ of the deformed tensile test specimen, the orientation of the habit plane, and the magnitude of the external stress $\left(\sigma_{a}\right)$. According to (20.3), the mechanical work consists of two terms: the first term is the shear stress $\left(\tau_{r}\right)$ responsible for the shear strain $\left(\gamma_{0}\right)$ parallel to the habit plane and the second term is the normal stress $\left(\sigma_{\mathrm{N}}\right)$ responsible for the volume expansion normal to the habit plane $\left(\varepsilon_{0}\right)$ [23]. Experimental values of the investigated steels are shown in (Table 20.2).

$$
W_{\text {mech }}=V_{\mathrm{m}}\left[\tau_{r} * \gamma_{0}+\sigma_{\mathrm{N}} * \epsilon_{0}\right]
$$

Assuming that the tensile load is applied at an angle $(\theta)$ to a potential habit plane normal, the normal and shear components of stress can be deduced from the Mohr's circle construction for tension as shown in Fig. 20.4.

Equation (20.4) can be derived by inserting the stress components from Fig. 20.4 in (20.3).

$$
W_{\text {mech }}=V_{\mathrm{m}}\left[\sigma_{a / 2} * \gamma_{0} \sin (2 \theta)+\sigma_{a / 2} * \epsilon_{0}(1+\cos (2 \theta))\right]
$$

The term $W_{\min }$ in Fig. 20.2 can be estimated by inserting the triggering stress for martensite formation at temperatures between $M_{\mathrm{s}}$ and $M_{\mathrm{d}}$ in (20.4). The summation of this term with the chemical driving force for $\alpha^{\prime}$-martensite formation $\left(\Delta G_{\mathrm{chem}}^{\gamma \rightarrow \alpha^{\prime}}\right.$ ) gives an estimate of the critical driving force for martensite formation. The maximum applicable mechanical work contributing to the formation of martensite $\left(W_{\max }\right)$, on 


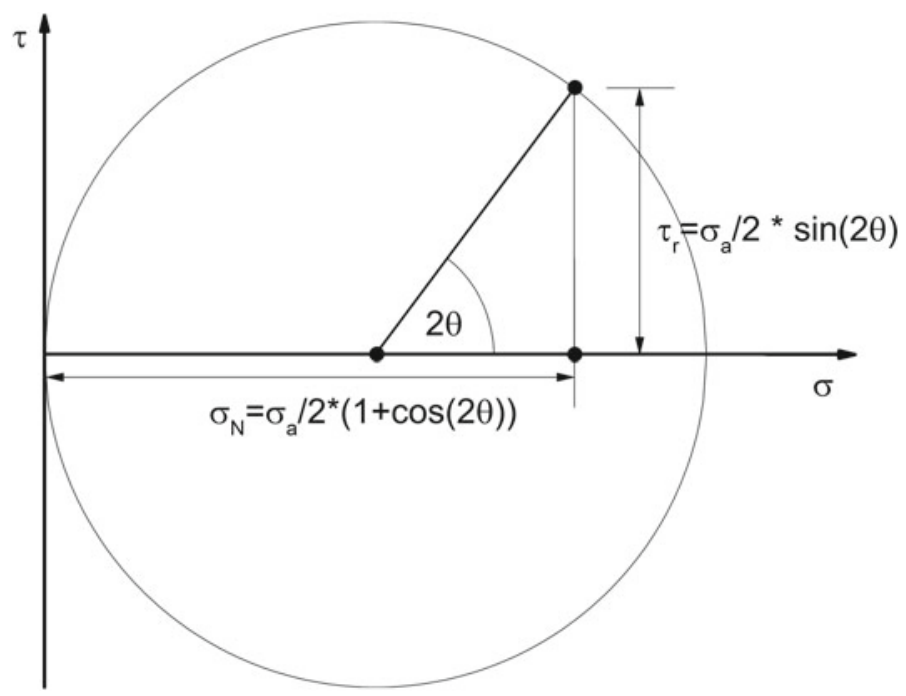

Fig. 20.4 Mohr's circle for tension showing shear $\left(\tau_{r}\right)$ and normal $\left(\sigma_{\mathrm{N}}\right)$ components of stress as functions of the applied stress $\left(\sigma_{a}\right)$ and the angle between the potential habit plane normal and loading direction $(\theta)$ [23]

Table 20.2 Lattice parameters of austenite and martensite and the corresponding shear strain $\left(\gamma_{0}\right)$, volume expansion $\left(\varepsilon_{0}\right)$, and the angle $\theta_{\max }$

\begin{tabular}{l|l|l|l|l|l|l}
\hline Alloy & $a_{\gamma}(\AA)$ & $a_{\alpha^{\prime}}(\AA)$ & $c_{\alpha^{\prime}}(\AA)$ & $\gamma_{0}(-)$ & $\varepsilon_{0}(-)$ & $\theta_{\max }\left({ }^{\circ}\right)$ \\
\hline X5CrNi18-10 & 3.589 & 2.873 & 2.873 & 0.2260 & 0.0253 & 41.81 \\
\hline X3CrMnNi16-7-3 & 3.596 & 2.878 & 2.878 & 0.2263 & 0.0230 & 42.10 \\
\hline X3CrMnNi16-7-6 & 3.594 & 2.875 & 2.875 & 0.2266 & 0.0225 & 42.16 \\
\hline X3CrMnNi16-7-9 & 3.593 & 2.873 & 2.873 & 0.2318 & 0.0267 & 41.72 \\
\hline X15CrNiMnN19-4-3 & 3.591 & 2.884 & 2.858 & 0.2258 & 0.0259 & 41.73 \\
\hline
\end{tabular}

the other hand, can be calculated by inserting the true stress at the onset of necking in (20.4). To calculate the angle $\theta$ associated with the maximum value of $W_{\text {mech }}$, the differential of (20.4) with respect to $\theta$ must be set to zero. This condition is represented in (20.5) [23].

$$
\frac{\mathrm{d} W_{\text {mech }}}{\mathrm{d} \theta}=0 \Rightarrow \tan 2 \theta_{\max }=\frac{\gamma_{0}}{\varepsilon_{0}}
$$

The $\varepsilon_{0}, \gamma_{0}$, and $\theta_{\max }$ values are influenced by the lattice parameters of austenite and martensite, which in turn depend on the chemical composition. To determine these quantities for the investigated steel, the martensite crystallography theory due to Wechsler-Lieberman-Read was used [31-33]. The following equations enable to calculate the shear and dilatational components of the invariant-plane strain based 
on the lattice parameters of austenite $\left(a_{\gamma}\right)$ and martensite $\left(a_{\alpha}\right)$ [31]:

$$
\begin{gathered}
\gamma_{0}=\left[\left(\frac{2 * a_{\alpha}^{2}}{a_{\gamma}^{2}}-1\right) *\left(1-\frac{2 * a_{\alpha}^{4}}{a_{\gamma}^{4}}\right)\right]^{\frac{1}{2}} \\
\epsilon_{0}=\frac{V_{\alpha}}{V_{\gamma}}-1=\frac{2 * a_{\alpha}^{3}}{a_{\gamma}^{3}}-1 .
\end{gathered}
$$

\subsection{Model Development Based on an Austenitic X5CrNi18-10 Steel}

Figure 20.5 shows the flow curves (dashed lines) of the X5CrNi18-10 steel (AISI 304) at various temperatures. With decreasing temperature, the flow curves shift to higher stresses. The uniform tensile elongation values, in contrast, pass through a maximum at intermediate tensile testing temperatures. In the temperature range of $140-23{ }^{\circ} \mathrm{C}$, the elongation increases as the temperature decreases. The highest elongation was reached at room temperature and decreased again at lower deformation temperatures. Three solid lines are superimposed on the flow curves in Fig. 20.5. Two of these lines indicate the inflection points on the flow curves, namely where the sign of

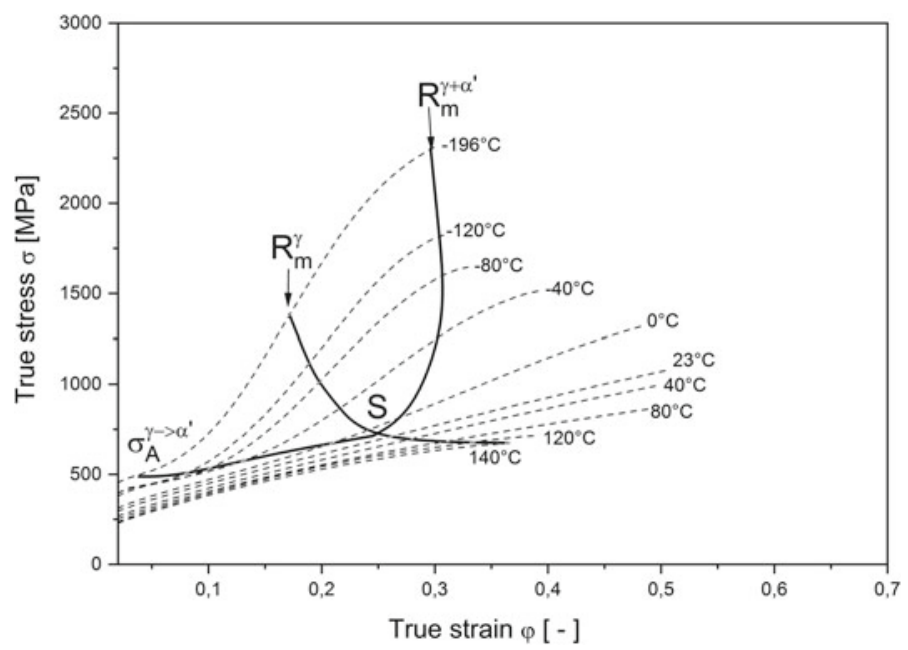

Fig. 20.5 Temperature dependent flow curves for the $\mathrm{X} 5 \mathrm{CrNi} 18-10$ steel. Superimposed on the flow curves are the trigger stress $\sigma_{A}^{\gamma \rightarrow \alpha^{\prime}}$, the tensile strength of the austenite $R_{m}^{\gamma}$ and tensile strength of the steel $R_{m}^{\gamma+\alpha^{\prime}}$ with neglected strengthening contributions other than the deformation-induced martensite formation [18] 
the second derivative of the flow curves reverses. The inflection points only occur for the stress-strain curves obtained at temperatures below $23^{\circ} \mathrm{C}$. The first inflection point, marked $\sigma_{A}^{\gamma \rightarrow \alpha^{\prime}}$ in Fig. 20.5, represents the triggering stress for the deformationinduced martensite formation. According to Weiß et al., the second inflection point, marked $R_{m}^{\gamma}$, corresponds to the tensile strength of the austenite [18, 28]. The first and second inflection points are associated with a minimum and a maximum in the strain-hardening rate, respectively. The third line, marked $R_{m}^{\gamma+\alpha^{\prime}}$ in Fig. 20.5, indicates the tensile strength level expected if the strengthening contributions other than the deformation-induced martensite formation are neglected [18, 28].

The point marked with " $S$ " in Fig. 20.5 almost lies on the $23{ }^{\circ} \mathrm{C}$ curve and may be identified with the approximate stress and strain coordinates of $705 \mathrm{MPa}$ and 0.28 , respectively. The point $S$ denotes where the first $\left(\sigma_{A}^{\gamma \rightarrow \alpha^{\prime}}\right)$ and second $\left(R_{m}^{\gamma}\right)$ inflection points of the flow curve coincide. This means that the triggering stress $\sigma_{A}^{\gamma \rightarrow \alpha^{\prime}}$ and the tensile strength $R_{m}^{\gamma}$ of the austenite are equal, which defines the $M_{\mathrm{d}}^{\gamma \rightarrow \alpha^{\prime}}$ temperature. The formation of martensite primarily occurs via $\gamma \rightarrow \varepsilon \rightarrow \alpha^{\prime}$ formation. However, the martensitic phase transformation via $\gamma \rightarrow \alpha^{\prime}$ martensite formation is possible too $[18,28]$.

Figure 20.6 shows the measured fractions of $\varepsilon$ - and $\alpha^{\prime}$-martensite in tensile specimens tested at various temperatures until the onset of necking. As the testing temperature decreased from 140 to $40{ }^{\circ} \mathrm{C}$, the $\varepsilon$-martensite fraction increased continuously to a maximum level of approximately $17 \%$. At temperatures between 40 and $23{ }^{\circ} \mathrm{C}$, the fraction of $\varepsilon$-martensite decreased, reaching zero at room temperature. In the

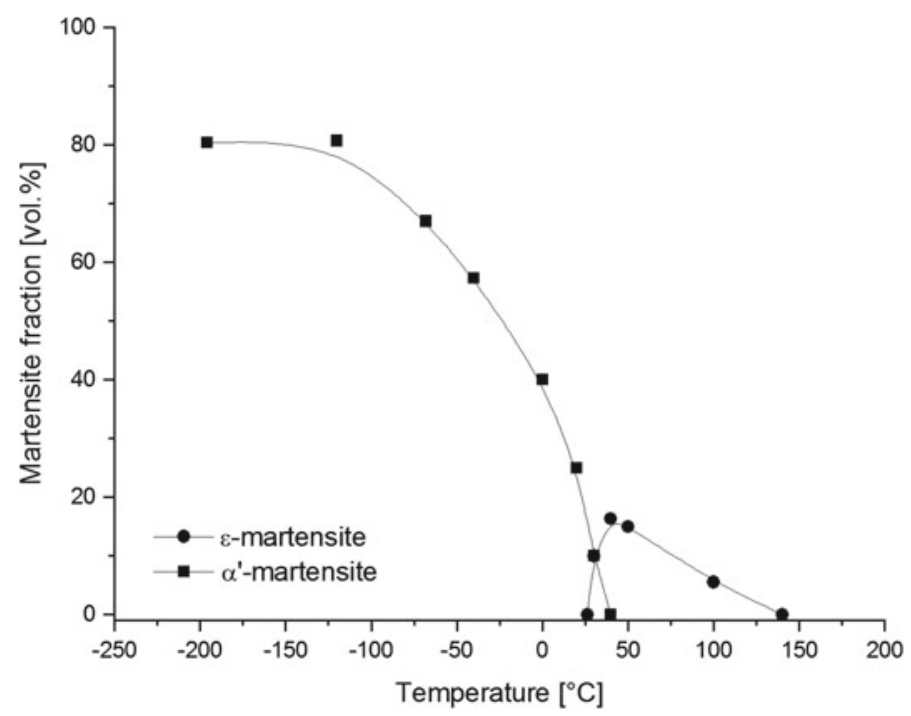

Fig. 20.6 Temperature dependence of $\varepsilon$ - and $\alpha^{\prime}$-martensite contents in tensile specimens strained in uniaxial tension until the onset of necking [18] 


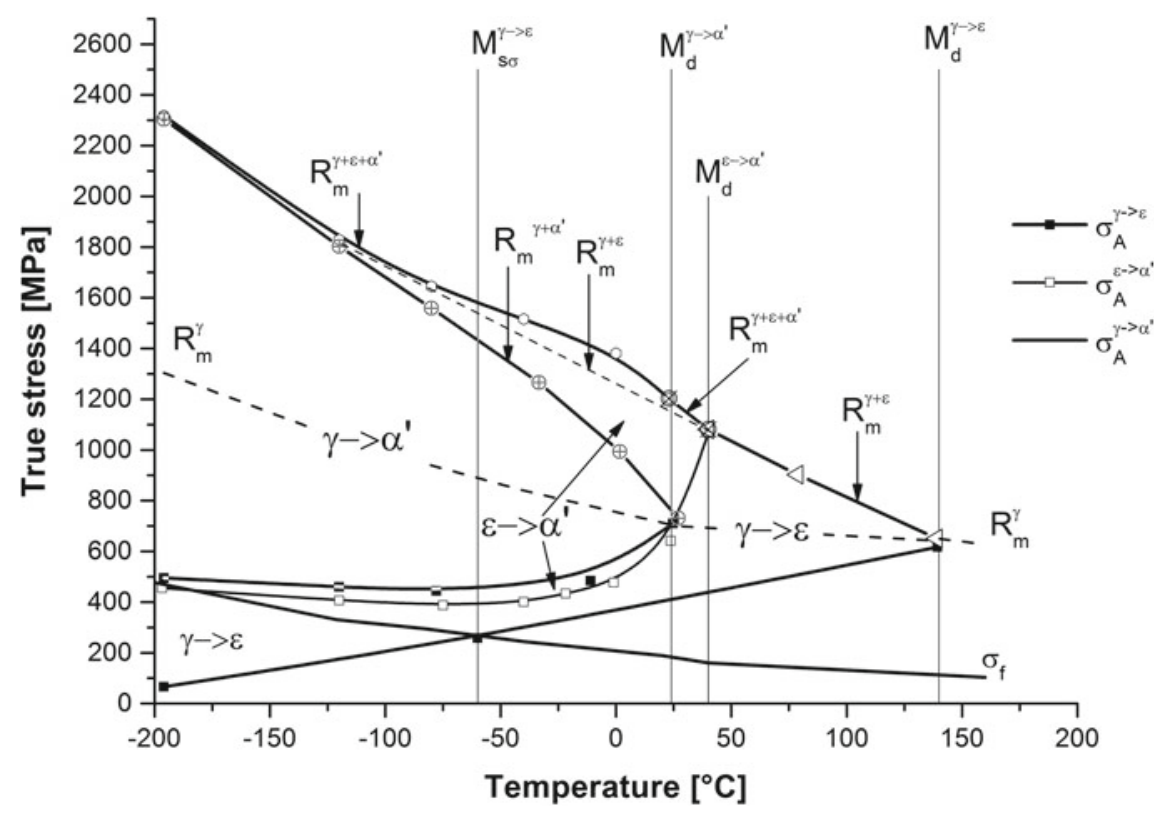

Fig. 20.7 Stress-temperature-transformation diagram (STT) for the X5CrNi18 10 steel [18]

temperature range between $40^{\circ} \mathrm{C}$ and room temperature, the decrease in the fraction of $\varepsilon$-martensite was almost equal to the increase in the $\alpha^{\prime}$-martensite fraction $[18,28]$.

Figure 20.7 shows the Stress-Temperature-Transformation (STT) diagram for the X5CrNi18-10 steel. The yield stress $\sigma_{f}$, the triggering stresses $\sigma_{A}^{\gamma \rightarrow \varepsilon}, \sigma_{A}^{\varepsilon \rightarrow \alpha^{\prime}}$ and $\sigma_{A}^{\gamma \rightarrow \alpha^{\prime}}$ and on the other hand the corresponding tensile strengths $R_{m}^{\gamma+\varepsilon}, R_{m}^{\gamma+\varepsilon+\alpha^{\prime}}$ and $R_{m}^{\gamma+\alpha^{\prime}}$ are shown in the diagram. The triggering stress $\sigma_{A}^{\gamma \rightarrow \alpha^{\prime}}$ was estimated from the first inflection point of the flow curve. The triggering stresses for the $\gamma \rightarrow \epsilon$ and $\varepsilon \rightarrow \alpha^{\prime}$ martensitic transformations were obtained experimentally through microstructural analyses of interrupted tensile test specimens. The tensile strength of austenite $R_{m}^{\gamma}$ was estimated by the extrapolation of the tensile strength values above $M_{\mathrm{d}}^{\gamma \rightarrow \varepsilon}$ to lower temperatures. The tensile strength $R_{m}^{\gamma+\varepsilon}$ below $M_{\mathrm{d}}^{\varepsilon \rightarrow \alpha^{\prime}}$ temperature is a linear extrapolation of the course between $M_{\mathrm{d}}^{\varepsilon \rightarrow \alpha^{\prime}}$ and $M_{\mathrm{d}}^{\gamma \rightarrow \varepsilon}$ temperature. The intersection of triggering stress with specific tensile strengths $\left(R_{m}^{\gamma+\varepsilon} ; R_{m}^{\gamma+\varepsilon+\alpha^{\prime}} ; R_{m}^{\gamma+\alpha^{\prime}}\right)$ for a given strain-induced transformation defines the $\mathrm{M}_{\mathrm{d}}$ temperature corresponding to that transformation, shown in Fig. 20.7. The $M_{\mathrm{d}}^{\gamma \rightarrow \varepsilon}, M_{\mathrm{d}}^{\varepsilon \rightarrow \alpha^{\prime}}$ and $M_{\mathrm{d}}^{\gamma \rightarrow \alpha^{\prime}}$ temperatures are approximately $413 \mathrm{~K}\left(140{ }^{\circ} \mathrm{C}\right), 313 \mathrm{~K}\left(40{ }^{\circ} \mathrm{C}\right)$, and $296 \mathrm{~K}\left(23{ }^{\circ} \mathrm{C}\right)$, respectively. The $M_{\mathrm{S} \sigma}^{\gamma \rightarrow \varepsilon}$ temperature is located at the intersection point of yield stress $\sigma_{f}$ and the triggering stress $\sigma_{A}^{\gamma \rightarrow \varepsilon}$ near $213 \mathrm{~K}\left(-60{ }^{\circ} \mathrm{C}\right)$. The stress region, bounded by the triggering stress and the corresponding tensile strength for each martensitic transformation, marks the stress interval in which the relevant transformation occurs $\left(\gamma \rightarrow \varepsilon / \varepsilon \rightarrow \alpha^{\prime} / \gamma \rightarrow \alpha^{\prime}\right)$. The wider the transformation interval, the 
higher are the formed fractions of $\varepsilon$ und $\alpha^{\prime}$ martensite and, hence, the tensile strength of the steel. Below $M_{\mathrm{d}}^{\gamma \rightarrow \alpha^{\prime}}$ temperature, the $\varepsilon$-martensite only formed before the $\alpha^{\prime}$-martensite formation was triggered. As soon as the triggering stress $\sigma_{A}^{\gamma \rightarrow \alpha^{\prime}}$ was reached, $\varepsilon$-martensite was replaced by the $\alpha^{\prime}$-martensite $[18,28]$.

The strength contributions due to the induced deformation mechanisms in the austenite could be derived from the STT diagram in the following form. The summation of all strength contributions yields the true stress corresponding to the tensile strength $R_{m}^{\text {steel }}$ of the steel. At temperatures above the $M_{\mathrm{d}}^{\gamma \rightarrow \varepsilon}$ temperature, the strain hardening of austenite occurred only via dislocation glide and increase of dislocation density. Under these circumstances, the tensile strength $R_{m}^{\text {steel }}$ is equal to the tensile strength $R_{m}^{\gamma}$ of austenite, as shown in (20.8) $[18,28]$.

$$
R_{m}^{\text {steel }}=R_{m}^{\gamma}
$$

In the temperature range between the $M_{\mathrm{d}}^{\gamma \rightarrow \varepsilon}$ and $M_{\mathrm{d}}^{\varepsilon \rightarrow \alpha^{\prime}}$ temperatures, two deformation processes are superimposed in the austenite. These were the strain-induced $\varepsilon$-martensite formation and dislocation glide. As (20.9) indicates, the tensile strength of the steel in this temperature range is the sum of the tensile strength of austenite and the strengthening due to the $\gamma \rightarrow \varepsilon$ transformation $\Delta \sigma^{\gamma \rightarrow \varepsilon}[18,28]$.

$$
R_{m}^{\text {steel }}=R_{m}^{\gamma+\varepsilon}=R_{m}^{\gamma}+\Delta \sigma^{\gamma \rightarrow \varepsilon}
$$

In the temperature range between the $M_{\mathrm{d}}^{\varepsilon \rightarrow \alpha^{\prime}}$ and $M_{\mathrm{d}}^{\gamma \rightarrow \alpha^{\prime}}$ temperatures, the dislocation glide, the strain-induced $\varepsilon$ martensite formation, and the strain-induced $\varepsilon \rightarrow \alpha^{\prime}$ martensite formation processes are superimposed. The tensile strength $R_{m}^{\text {steel }}$ can be calculated in this temperature range by using $(20.10)[18,28]$.

$$
R_{m}^{\text {steel }}=R_{m}^{\gamma+\varepsilon+\alpha^{\prime}}=R_{m}^{\gamma}+\Delta \sigma^{\gamma \rightarrow \varepsilon}+\Delta \sigma^{\varepsilon \rightarrow \alpha^{\prime}}
$$

Below $M_{\mathrm{d}}^{\gamma \rightarrow \alpha^{\prime}}$ temperature, the strain-induced $\gamma \rightarrow \alpha^{\prime}$ martensite is increasing the tensile strength $R_{m}^{\text {steel }}$ of the steel by an amount equal to $\Delta \sigma^{\gamma \rightarrow \alpha^{\prime}}$, shown in (20.11) $[18,28]$.

$$
R_{m}^{\text {steel }}=R_{m}^{\gamma+\varepsilon+\alpha^{\prime}}=R_{m}^{\gamma}+\Delta \sigma^{\gamma \rightarrow \varepsilon}+\Delta \sigma^{\varepsilon \rightarrow \alpha^{\prime}}+\Delta \sigma^{\gamma \rightarrow \alpha^{\prime}}
$$

The behavior described in Fig. 20.7 and (20.8)-(20.11) arises from the interplay between the strain-induced $\varepsilon$ or $\alpha^{\prime}$ martensite formation and the dislocation glide in the austenite. Referring to the STT diagram, the stress increments achieved by various deformation-induced mechanisms can be obtained according to Weiß et al. [18, 28] by a procedure involving mirroring of the triggering stress values with respect to the tensile strength of the austenite $\left(R_{m}^{\gamma}\right)$.

The strain contributions due to deformation-induced mechanisms can be summarized using the so-called deformation-temperature-transformation (DTT) diagrams. 


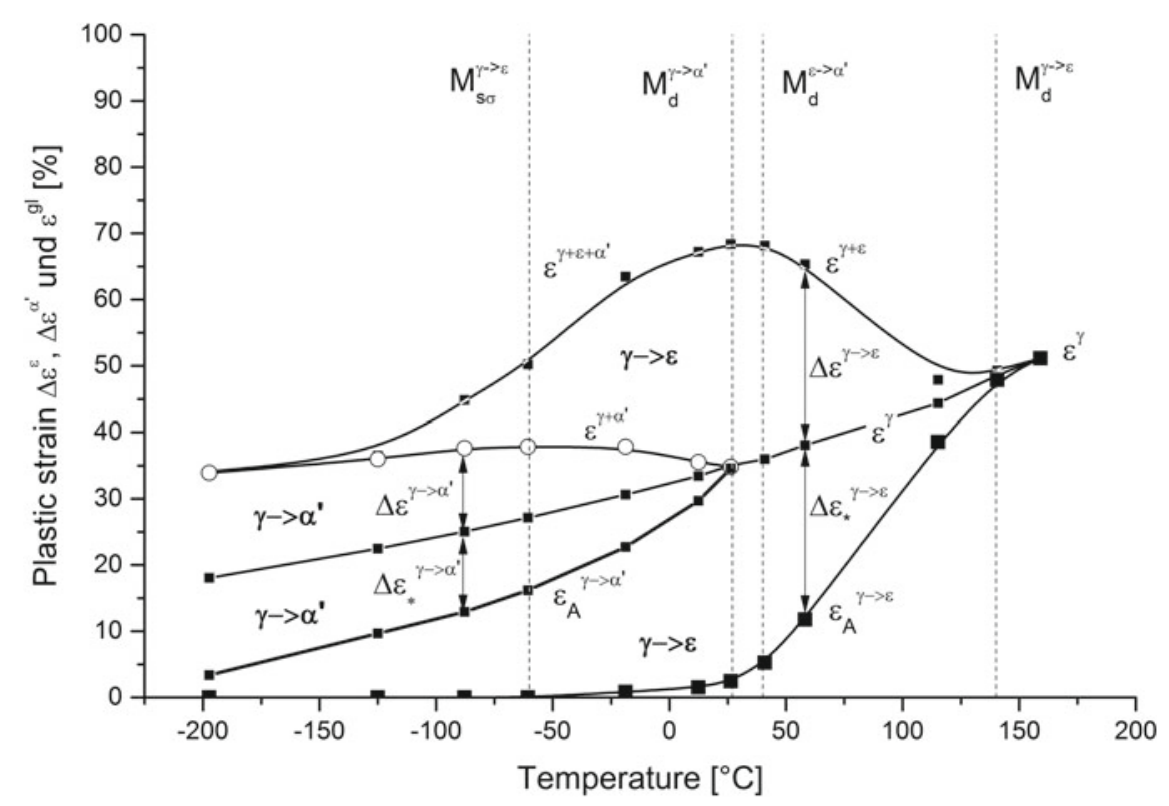

Fig. 20.8 Deformation-temperature-transformation diagram (DTT) of the X5CrNi18-10 steel [18]

Figure 20.8 shows the DTT diagram for the X $5 \mathrm{CrNi} 18-10$ steel where the plastic elongations associated with the strain-induced $\gamma \rightarrow \varepsilon \rightarrow \alpha^{\prime}$ and $\gamma \rightarrow \alpha^{\prime}$ deformation processes are indicated $[18,28]$.

The uniform elongation of the steel (uppermost curve in Fig. 20.8), uniform elongation of the austenite $\varepsilon^{\gamma}$, and the elongations $\varepsilon_{A}^{\gamma \rightarrow \varepsilon}$ and $\varepsilon_{A}^{\gamma \rightarrow \alpha^{\prime}}$ corresponding to the tensile trigger stress values $\sigma_{A}^{\gamma \rightarrow \varepsilon}$ and $\sigma_{A}^{\gamma \rightarrow \alpha^{\prime}}$, respectively, are shown in Fig. 20.8. In addition, the plastic elongations $\Delta \varepsilon^{\gamma \rightarrow \varepsilon}$ and $\Delta \varepsilon^{\gamma \rightarrow \alpha^{\prime}}$ contributed by the straininduced $\varepsilon$-martensite and $\alpha^{\prime}$-martensite formation, respectively, as well as the values $\Delta \varepsilon_{*}^{\gamma \rightarrow \varepsilon}$ and $\Delta \varepsilon_{*}^{\gamma \rightarrow \alpha^{\prime}}$ contributed by the glide in the austenite, are shown in Fig. 20.8. It is also shown that the elongation values $\Delta \varepsilon^{\gamma \rightarrow \varepsilon}$ and $\varepsilon_{*}^{\gamma \rightarrow \varepsilon}$ as well as $\Delta \varepsilon^{\gamma \rightarrow \alpha^{\prime}}$ and $\Delta \varepsilon_{*}^{\gamma \rightarrow \alpha^{\prime}}$ are equal [28]. The measured plastic elongations are a consequence of deformation-induced martensite formation as well as the plastic elongation pertaining to the induced glide processes in the austenite in the transformation range. Equations (20.12)-(20.14) describe the plastic elongation behavior of the X5CrNi18 10 steel in various temperature intervals with different deformation mechanisms. Equation (20.12) applies above the $M_{\mathrm{d}}^{\gamma \rightarrow \varepsilon}$ temperature, in which the uniform elongation of the steel $\left(\varepsilon^{\text {steel }}\right)$ is equal to the uniform elongation of the austenite $\left(\varepsilon^{\gamma}\right)[18,28]$.

$$
\varepsilon^{\text {steel }}=\varepsilon^{\gamma}
$$

Between $M_{\mathrm{d}}^{\gamma \rightarrow \varepsilon}$ and $M_{\mathrm{d}}^{\gamma \rightarrow \alpha^{\prime}}$ temperatures (20.13) applies. 


$$
\varepsilon^{\text {steel }}=\varepsilon^{\gamma+\varepsilon}=\varepsilon^{\gamma}+\Delta \varepsilon^{\gamma \rightarrow \varepsilon}
$$

Below the $M_{\mathrm{d}}^{\gamma \rightarrow \alpha^{\prime}}$ temperature (20.14) applies.

$$
\varepsilon^{\text {steel }}=\varepsilon^{\gamma+\varepsilon+\alpha^{\prime}}=\varepsilon^{\gamma}+\Delta \varepsilon^{\gamma \rightarrow \varepsilon}+\Delta \varepsilon^{\gamma \rightarrow \alpha^{\prime}}
$$

At the $M_{\mathrm{d}}^{\gamma \rightarrow \varepsilon}$ temperature, the plastic elongation value $\varepsilon_{A}^{\gamma \rightarrow \varepsilon}$ coincides with the uniform elongation of the austenite $\left(\varepsilon^{\gamma}\right)$. Below that temperature, the anomalous temperature dependence of the uniform elongation $\left(\varepsilon^{\text {steel }}\right)$, associated with noticeable ductility enhancement at lower temperatures, begins. At the $M_{\mathrm{d}}^{\gamma \rightarrow \alpha^{\prime}}$ temperature, the uniform elongation of the steel reaches a maximum. Below the $M_{\mathrm{s} \sigma}^{\gamma \rightarrow \varepsilon}$ temperature, the stress-induced $\varepsilon$ martensite formation begins, which does not lead to a plastic elongation. In the $\gamma \rightarrow \varepsilon \rightarrow \alpha^{\prime}$ transformation range, the plastic elongation $\Delta \varepsilon^{\gamma \rightarrow \varepsilon}$ contributed by the strain-induced $\varepsilon$-martensite formation equaled the plastic elongation value $\Delta \varepsilon_{*}^{\gamma \rightarrow \varepsilon}$ contributed by the glide in the austenite. The X5CrNi18-10 steel serves as an example for a method to describe the shear and glide processes occurring in the austenite. It is assumed that no glide processes were activated in the strain-induced $\varepsilon$ and $\alpha^{\prime}$ martensite phases. Strength and ductility contributions by the induced glide processes in the martensitic phases must be taken into account when spontaneous $\varepsilon$ - or $\alpha^{\prime}$-martensite, which raise the yield strength of the steel, are present in the starting microstructure [18, 28].

\subsection{Effect of Nickel on the Deformation Mechanisms of Metastable CrMnNi Cast Steels}

To describe the influence of chemical composition on the deformation mechanisms, the $\mathrm{X} 3 \mathrm{CrMnNi}$ 16-7-3, $\mathrm{X} 3 \mathrm{CrMnNi}$ 16-7-6 and $\mathrm{X} 3 \mathrm{CrMnNi}$ 16-7-9 cast steels with primarily austenitic microstructures have been developed [5, 34]. The true-stress versus true-strain curves of the investigated steels are shown in Fig. 20.9. These flow curves, obtained at various temperatures, are the basis for the development of STT and DTT diagrams [19]. The yield strength, tensile strength, and uniform elongation can be determined directly from the flow curves. To determine the triggering stress $\left(\sigma_{A}^{\gamma \rightarrow \alpha^{\prime}}\right)$ for the deformation-induced $\alpha^{\prime}$-martensite formation, the first derivatives of the flow curves, namely the work hardening rate, has to be calculated. A typical steel with deformation-induced $\alpha^{\prime}$-martensite formation shows two inflection points. The first inflection point corresponds to the triggering stress for the austenite to martensite formation. The second inflection point, on the other hand, can be correlated with the maximum of deformation-induced $\alpha^{\prime}$-martensite formation rate [21]. In the case of deformation-induced twinning or $\varepsilon$-martensite formation, no inflection point is observed. Therefore, the triggering stress for twinning or $\varepsilon$-martensite formation has to be determined by microstructural investigations after interrupted tensile tests [19]. 

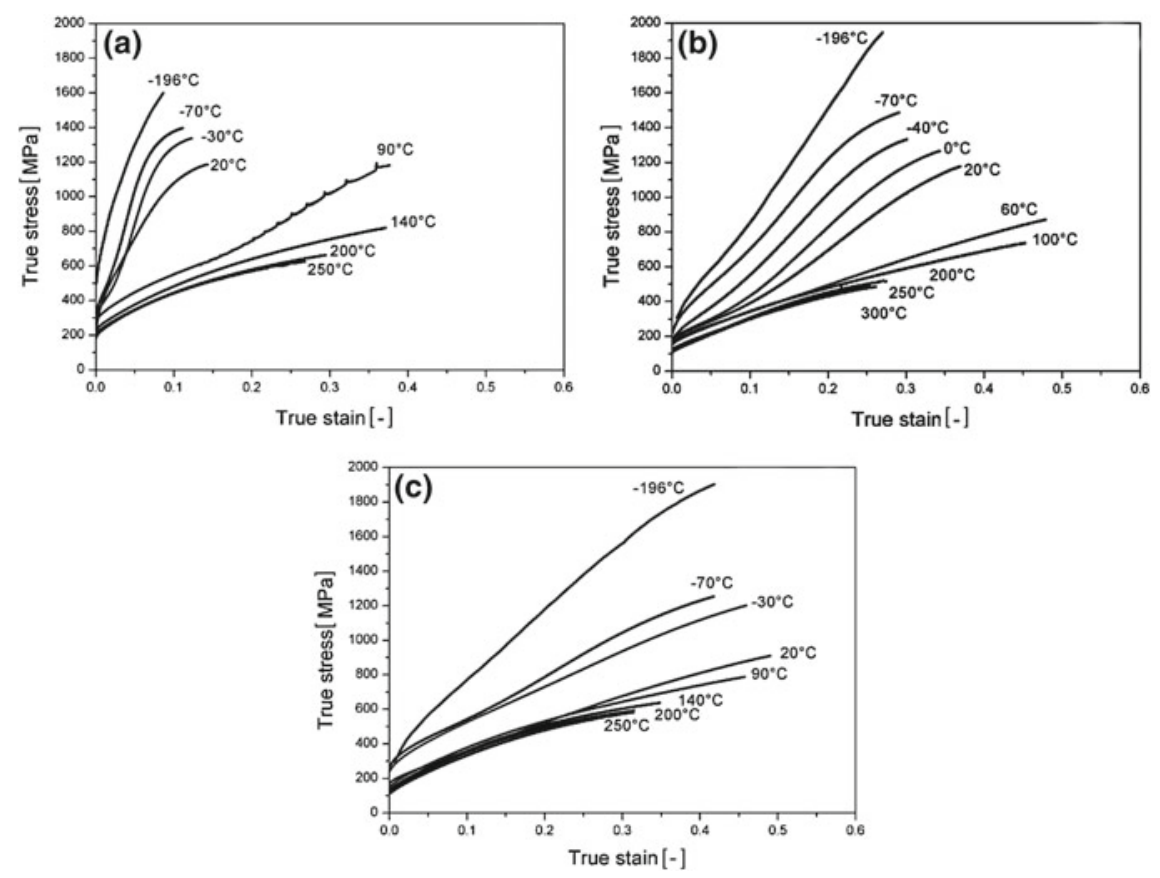

Fig. 20.9 True stress-strain curves for tensile specimens of a X3CrMnNi16-7-3, b X3CrMnNi167-6 and $\mathbf{c} \mathrm{X} 3 \mathrm{CrMnNi}$ 6-7-9 steel in the temperature range of -196 to $250^{\circ} \mathrm{C}[19,34]$

The STT and DTT diagrams for the steel X3CrMnNi16-7-3 are shown in Fig. 20.10. The triggering stresses and the tensile strength of the phases determine the stress-temperature fields for the deformation-induced processes (martensite formation, twinning, dislocations glide, etc.). The location of these fields depends on the chemical composition of the investigated steel [20]. All solid lines in the diagrams are experimentally determined. The dashed lines are predicted or approximated. In contrast to the X3CrMnNi16-7-6 and X3CrMnNi16-7-9 steels, the microstructure of the $\mathrm{X} 3 \mathrm{CrMnNi16}-7-3$ steel prior to tensile tests was not fully austenitic and the low austenite stability, the critical temperatures for deformation-induced twinning $T_{\mathrm{d}}^{\gamma \rightarrow \mathrm{Tw}}$ $\left(300{ }^{\circ} \mathrm{C}\right)$ and deformation-induced $\alpha^{\prime}$-martensite formation $M_{\mathrm{d}}^{\gamma+\varepsilon,(\mathrm{Tw}) \rightarrow \alpha^{\prime}}\left(140{ }^{\circ} \mathrm{C}\right)$ were higher compared to the other two steels [5, 20,34]. According to microstructural investigations, it is assumed that the $\varepsilon$ martensite formation occurs in the approximate temperature range $40-300{ }^{\circ} \mathrm{C}$. With increasing temperature and thus increasing stacking fault energy, deformation twinning replaces the $\varepsilon$ martensite formation [4]. Due to the low triggering stresses for the strain-induced $\alpha^{\prime}$-martensitic transformation at low temperatures, the $\varepsilon$-martensite formation is practically suppressed below room temperature. The maximum true strain of about 0.4 is reached at a temperature of approximately $120{ }^{\circ} \mathrm{C}$. The temperature anomaly of elongation (broad maximum in Fig. 20.11) in the steel $\mathrm{X} 3 \mathrm{CrMnNi16-7-3}$ is mainly caused by the strain-induced $\varepsilon$-TRIP [20]. The elongation contribution caused by the $\alpha^{\prime}$-martensite formation is 


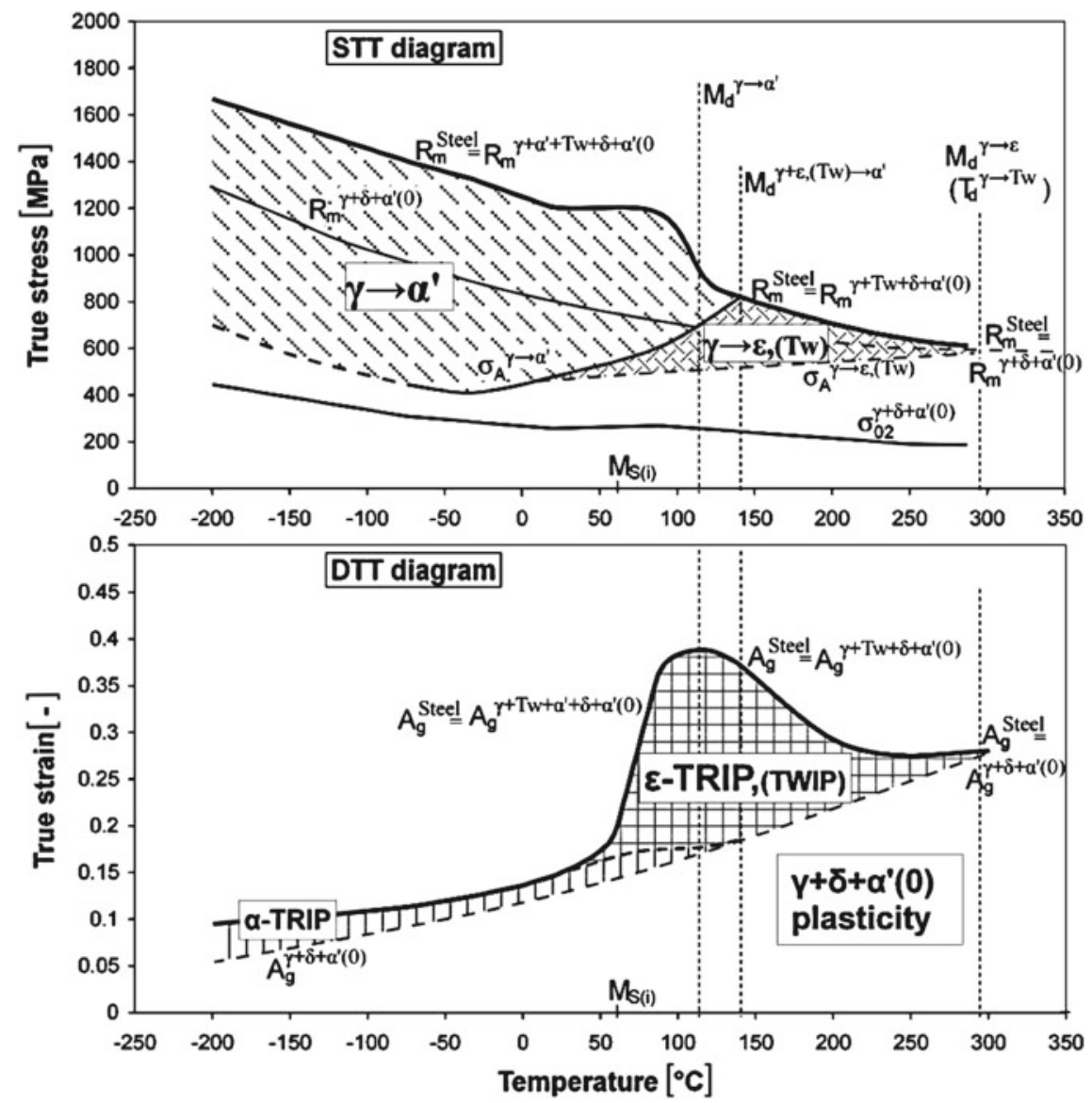

Fig. 20.10 STT and DTT diagrams for the X3CrMnNi16-7-3 steel [19]

negligible, because the $\alpha^{\prime}$-martensite after tensile tests is either deformation-induced or formed spontaneously.

Figure 20.11 shows the STT and DTT diagrams for the steel X3CrMnNi16-7-6. Compared to the $\mathrm{X} 3 \mathrm{CrMnNi16-7-3}$ steel, the critical transformation temperatures and the transformation fields are shifted to lower temperatures [35]. The $T_{\mathrm{d}}^{\gamma \rightarrow \mathrm{Tw}}$ temperature and the $M_{\mathrm{d}}^{\gamma+\varepsilon,(\mathrm{Tw}) \rightarrow \alpha^{\prime}}$ temperature are $250{ }^{\circ} \mathrm{C}$ and $100{ }^{\circ} \mathrm{C}$, respectively. In the temperature range between 0 and $50{ }^{\circ} \mathrm{C}$, the triggering stress for $\alpha^{\prime}$-martensite formation is very low. Therefore, the austenite transforms into martensite practically without twinning or $\varepsilon$-martensite formation. At a deformation temperature of $60{ }^{\circ} \mathrm{C}$, $\varepsilon$-martensite was found in the microstructure $[19,36]$. Additionally, the kinetics of the $\alpha^{\prime}$-martensite formation is shown in the STT diagram. Therefore, compared to the STT diagram of the X3CrMnNi16-7-3 steel, the STT diagram for the X3CrMnNi167-6 steel additionally includes the isolines for $\alpha^{\prime}$-martensite fraction as marked in 

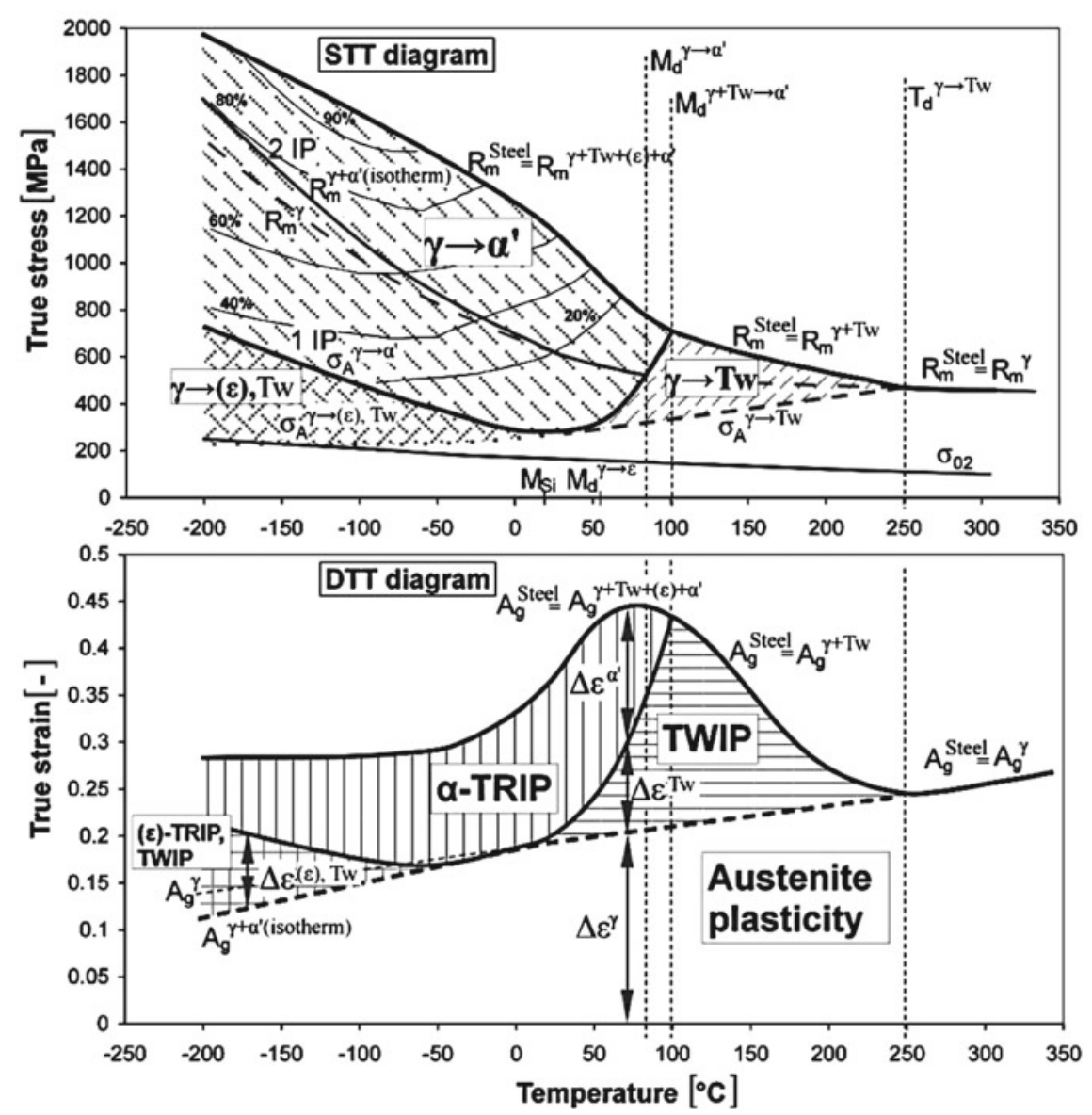

Fig. 20.11 STT and DTT diagrams for the X3CrMnNi16-7-6 steel [19]

the $\gamma \rightarrow \alpha^{\prime}$ transformation field. Moreover, the $\mathrm{X} 3 \mathrm{CrMnNi16}-7-6$ steel is capable of forming isothermal martensite, which is not taken into account in the STT diagram [20]. Accordingly, the stress values measured at the second inflection point are higher than the $R_{m}^{\gamma}$. This measurable stress $R_{m}^{\gamma+\alpha^{\prime} \text { (isotherm) }}$ enables an approximation of $R_{m}^{\gamma}$.

The uniform elongation $A_{g}^{\text {Steel }}$ of the X3CrMnNi16-7-6 steel, the uniform elongation of the austenite $A_{g}^{\gamma}$ and corresponding deformation mechanisms are shown in the DTT diagram in Fig. 20.11. Additionally, the elongation contributions due to the dislocations glide in the austenite $\Delta \varepsilon^{\gamma}$, deformation twinning $\Delta \varepsilon^{\mathrm{Tw}}$, and strain-induced martensite transformation $\Delta \varepsilon^{\alpha^{\prime}}$ are included in the DTT diagram. The temperature anomaly starting at $250{ }^{\circ} \mathrm{C}$ is a result of the stacking fault formation and twinning, which leads to an enhanced elongation with decreasing temperature [19, 20]. Below the $M_{\mathrm{d}}^{\gamma+\mathrm{Tw} \rightarrow \alpha^{\prime}}$ temperature $\left(80^{\circ} \mathrm{C}\right)$, the gradual replacement of stacking fault formation and twinning by $\alpha^{\prime}$-martensite formation leads a decrease in elongation. 
The STT and DTT diagrams for the steel $\mathrm{X} 3 \mathrm{CrMnNi16-7-9}$ are shown in Fig. 20.12. Compared to the steels X3CrMnNi16-7-3 and X3CrMnNi16-7-6, the stability of austenite is increased due to the higher Ni content. Accordingly, the critical temperatures are shifted to lower temperatures. The $T_{\mathrm{d}}^{\gamma \rightarrow \mathrm{Tw}}$ temperature is around $200{ }^{\circ} \mathrm{C}$. Austenite, which is deformed by twinning, transforms below $M_{\mathrm{d}}^{\gamma+\mathrm{Tw} \rightarrow \alpha^{\prime}}$ $\left(50{ }^{\circ} \mathrm{C}\right)$ into martensite. In the temperature range between -50 and $-70{ }^{\circ} \mathrm{C}$, the triggering stress for $\alpha^{\prime}$-martensite formation is very low, and austenite transforms directly into martensite almost without twinning. The maximum true strain of about 0.5 is reached at a temperature of $30^{\circ} \mathrm{C}$. A superposition of three deformation mechanisms - glide deformation of the austenite, TWIP effect, and TRIP effect-takes place at this temperature and causes the highest elongation.

The various austenite stabilities of the dendritic cast structure caused by the segregation of the alloying elements $\mathrm{Cr}$, $\mathrm{Mn}$, Ni during solidification of the austenitic
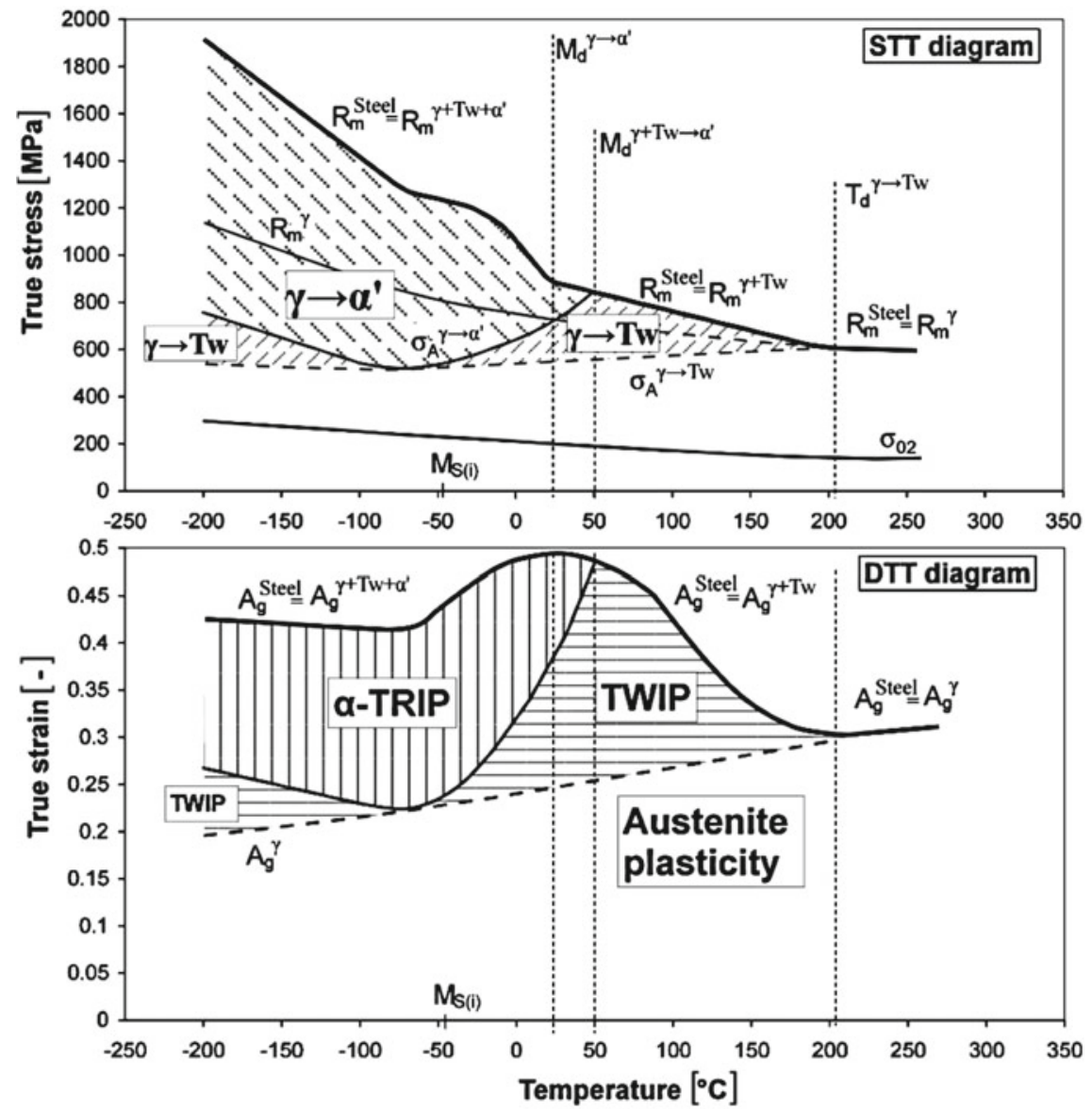

Fig. 20.12 STT and DTT diagrams for the X3CrMnNi 16-7-9 steel [19] 
steels X3CrMnNi 16-7-3/6/9 leads to a shift of critical temperatures. Accordingly, the center of dendrites are more metastable than interdendritic regions of austenite.

For further information the reader is revered to read the publication of Martin et al. [37] and Mola et al. [10].

\subsection{Thermodynamic-Mechanical Modeling Based on Austenitic CrMnNi-C-N Cast Steel}

Figure 20.13 shows the true stress-strain curves for the interstitially-alloyed X15CrNiMnN19-4-3 cast steel deformed until fracture at temperatures between 80 and $400{ }^{\circ} \mathrm{C}$. Carbon and nitrogen were alloyed to the steel to increase the strength by solid solution solidification. The highest elongation of $53 \%$ was reached at $60{ }^{\circ} \mathrm{C}$, which is almost equal to the $M_{\mathrm{d}}$-temperature $\left(70^{\circ} \mathrm{C}\right)$. The formation of $\alpha^{\prime}$-martensite at lower temperatures resulted in a pronounced strengthening and a steady decrease in elongation. Reduction of tensile elongation at temperatures below the $M_{\mathrm{d}}$ temperature is a common observation in austenitic stainless steels, including the steels discussed above [22]. The noticeable work hardening at $-80^{\circ} \mathrm{C}$ resulted in the highest (engineering) tensile strength of $1500 \mathrm{MPa}$, which correlates to a true tensile strength of $2000 \mathrm{MPa}$.

The phase fractions of martensite and austenite after tensile deformation until fracture at different temperatures is shown in Fig. 20.14. The steel does not form asquenched martensite at temperatures as low as $-196^{\circ} \mathrm{C}$. Therefore, the martensite contents in Fig. 20.14 represent the deformation-induced martensite only. The highest martensite content of about $81 \mathrm{vol} \%$ was formed during deformation at $-80{ }^{\circ} \mathrm{C}$.

To determine the deformation mechanisms activated during tensile tests, SEM investigations were carried out on tensile specimens deformed until fracture at $-80,70$ and $200{ }^{\circ} \mathrm{C}$ (Fig. 20.15). The tensile direction is horizontal aligned to the plane of view. ECCI image of Fig. 20.15a shows the presence of various operating

Fig. 20.13 True stress-strain curves of tensile specimens of the X15CrNiMnN19-4-3 cast steel in the temperature range of -80 to $400{ }^{\circ} \mathrm{C}$

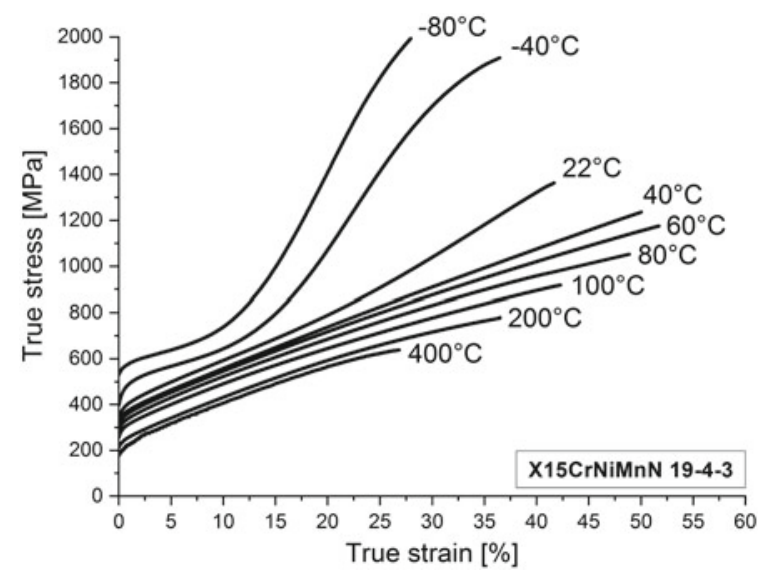




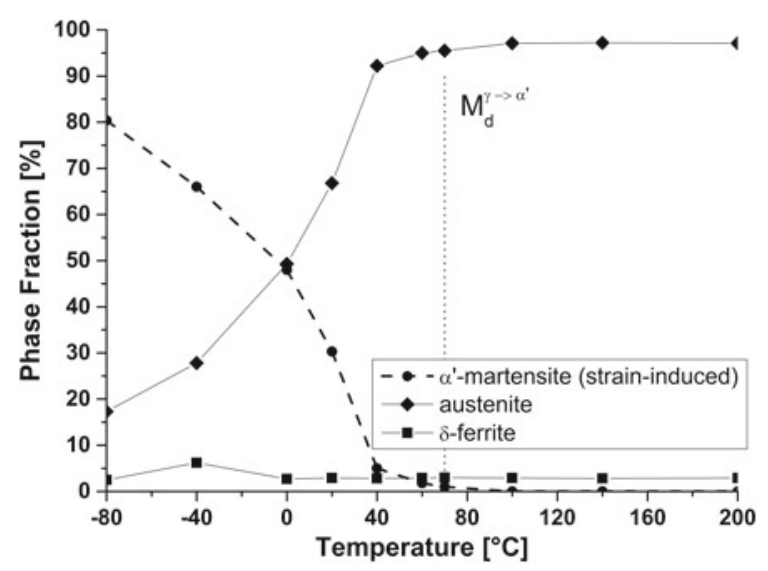

Fig. 20.14 Phase fractions in the microstructure of tensile specimens of the X15CrNiMnN19-4-3 steel tested at various temperatures
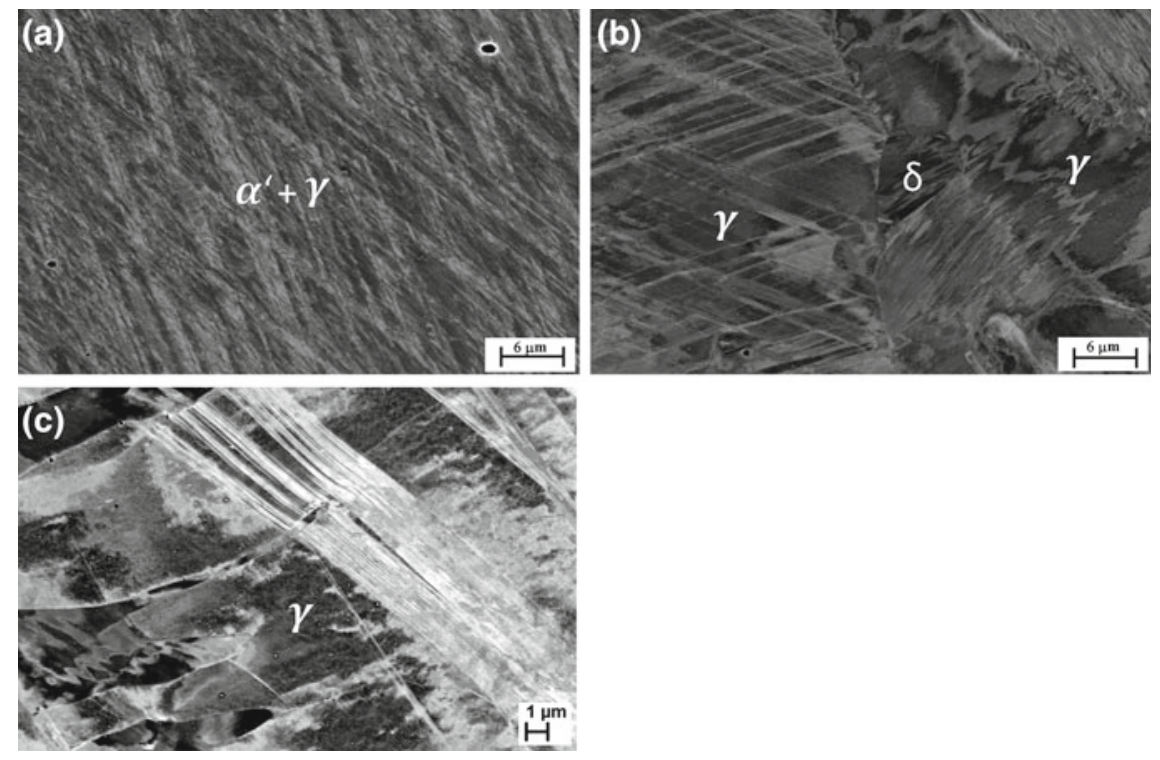

Fig. 20.15 Microstructures obtained after tensile deformation at different temperatures: ECCI micrographs of specimens deformed at $-80^{\circ} \mathrm{C}(\mathbf{a}), 70^{\circ} \mathrm{C}(\mathbf{b})$ and $200^{\circ} \mathrm{C}(\mathbf{c})$ of the $\mathrm{X} 15 \mathrm{CrNiMnN} 19$ 4-3 steel

straight deformation bands with $\alpha^{\prime}$-martensite in the microstructure of the specimen deformed at $-80{ }^{\circ} \mathrm{C}$. This indicates the dominance of planar glide due to the high activity of Shockley partial dislocations at $-80{ }^{\circ} \mathrm{C}$ [9]. According to the MSAT measurement results (Fig. 20.15) a large volume fraction of austenite transformed to 
$\alpha^{\prime}$-martensite. The ECCI image of the specimen tensile tested at $70{ }^{\circ} \mathrm{C}$ (Fig. 20.15b) shows two austenite grains with different microstructural characteristics. Whereas the microstructure of the austenite grain on the left resembles the microstructure shown in Fig. 20.15a, diffuse contrast changes in the austenite grain to the right imply the dominance of wavy glide [8, 38]. Abrupt transition in the glide mode across a grain boundary is more consistent with the differences in the crystallographic orientation of the neighboring grains than with the possible segregation of alloying elements in the cast steel. After all, the forces exerted on the leading and trailing partial dislocations of the primary slip system depend on the crystal orientation $[9,39]$. The ECCI image of the specimen deformed at $200{ }^{\circ} \mathrm{C}$ in Fig. 20.15c on the other hand shows only a diffuse contrast changes in the austenite grain what a dominance of wavy glide means. This sequence has been similarly observed in the $\mathrm{X} 3 \mathrm{CrMnNi16-7-6}$ steel $[4,5,40,41]$.

To describe the occurring deformation mechanisms during tensile loading, interrupted tensile tests with subsequent microstructure investigations have been performed. ECCI image and EBSD phase map of a tensile sample deformed at $0{ }^{\circ} \mathrm{C}$ to $800 \mathrm{MPa}$ are shown in Fig. 20.16. It is well established that the type of deformationinduced processes in austenitic steels depends on the stacking fault energy; as the stacking fault energy decreases, the deformation mechanism changes from perfect dislocation glide to deformation twinning, $\varepsilon$-martensite formation, and $\alpha^{\prime}$-martensite formation in that sequence [42]. Due to the coexistence of a small $\varepsilon$-martensite fraction in the deformation bands, the martensitic transformation according to the sequence $\gamma \rightarrow \varepsilon \rightarrow \alpha^{\prime}$ (Fig. 20.16b) is very likely. The mechanism of formation of deformation-induced twins and $\varepsilon$-martensite is very similar and only differs in the stacking sequence of $\{111\} \gamma$ close-packed planes; thus stacking faults on successive $\{111\} \gamma$ planes generate deformation twins, whereas their overlap on every second $\{111\} \gamma$ plane results in the formation of $\varepsilon$-martensite [4]. Accordingly, these two byproducts of stacking faults have been observed to coexist in the microstructure of deformed austenitic steels [43].
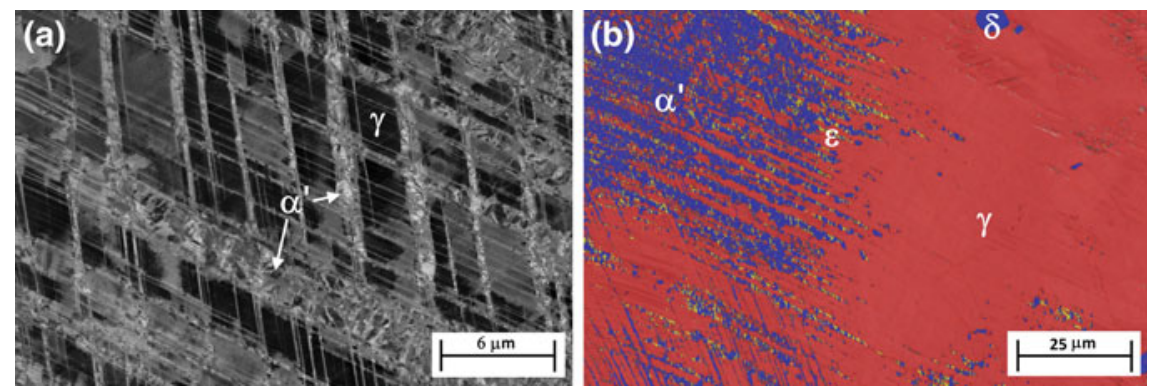

Fig. 20.16 Microstructures obtained after tensile testing at different temperatures: ECCI image and EBSD phase map of a specimen deformed at $0{ }^{\circ} \mathrm{C}$ to $800 \mathrm{MPa}$. In the EBSD phase map, red, yellow, and blue denote phases with fcc, hcp, and bcc crystal structures, respectively 


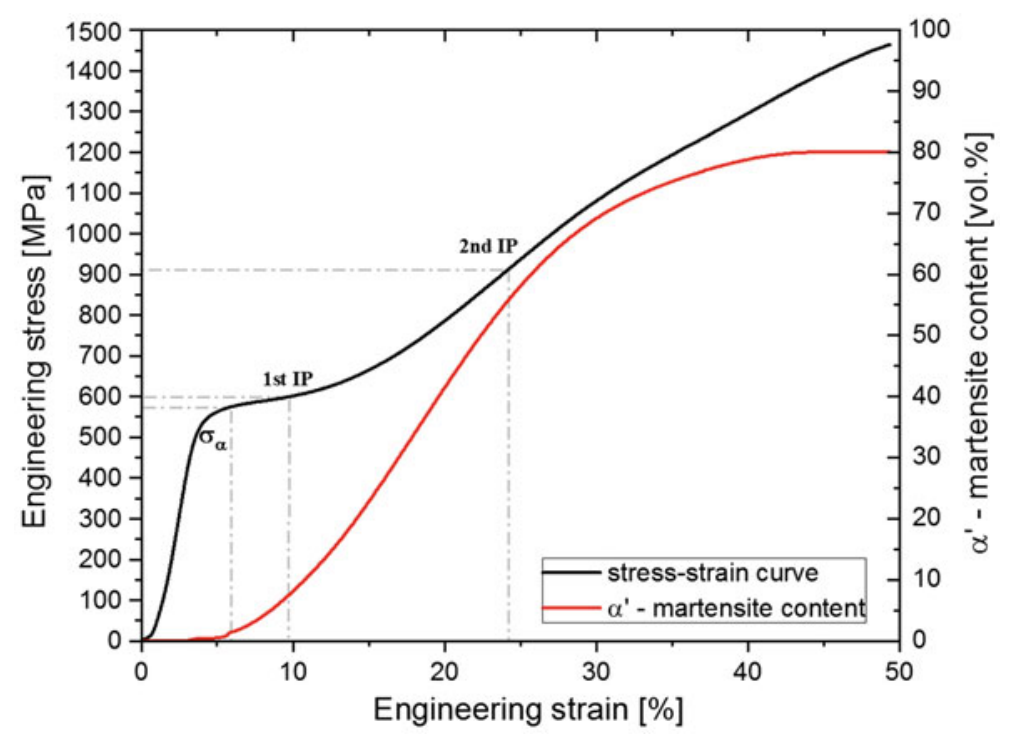

Fig. 20.17 Evolution of deformation-induced $\alpha^{\prime}$-martensite fraction during tensile deformation at $-80{ }^{\circ} \mathrm{C}$ of the $\mathrm{X} 15 \mathrm{CrNiMnN} 19-4-3$ steel superimposed on the stress-strain curve

In order to correlate the stress-strain curve with the deformation-induced $\alpha^{\prime}$-martensite fraction, the evolution of martensite fraction during tensile test at $-80{ }^{\circ} \mathrm{C}$, obtained from in situ magnetic measurements, is superimposed on the stress-strain curve (Fig. 20.17). The evolution of $\alpha^{\prime}$-martensite fraction with strain resembles the available literature data on the kinetics of deformation-induced martensite formation in metastable austenitic alloys. The increase in the work hardening rate caused by the deformation-induced formation of $\alpha^{\prime}$-martensite is known to cause a first inflection point in the stress-strain curve of metastable austenitic steels [36]. Taking the stress at which almost $1 \mathrm{vol} \% \alpha^{\prime}$-martensite has formed by deformation as the triggering stress for the deformation-induced $\alpha^{\prime}$-martensite formation $\left(\sigma_{A}\right)$, it does not match the first inflection point (IP) of the stress-strain curve. As marked in Fig. 20.17, the first inflection point during tensile deformation at $-40^{\circ} \mathrm{C}$ occurs after the formation of almost 3-5 vol\% martensite in the microstructure. In other words, the first inflection point gives a slightly overestimated approximation of the triggering stress. Between the first and second inflection points, the martensite formation rate remains almost constant [21].

The STT and DTT diagrams of the X15CrNiMnN19-4-3 are shown in Fig. 20.18. The area between the triggering stress and the tensile strength, marked $\gamma \rightarrow \alpha^{\prime}$ in Fig. 20.18, denotes the stress-temperature field favorable for the deformationinduced martensitic transformation. In different temperature ranges, different deformation mechanisms are activated. The dominant mechanisms are deformationinduced martensite formation below $M_{\mathrm{d}}$, deformation twinning between $M_{\mathrm{d}}$ and $T_{\mathrm{d}}$, and glide of perfect dislocations above $T_{\mathrm{d}}$ temperature. The temperature range where 

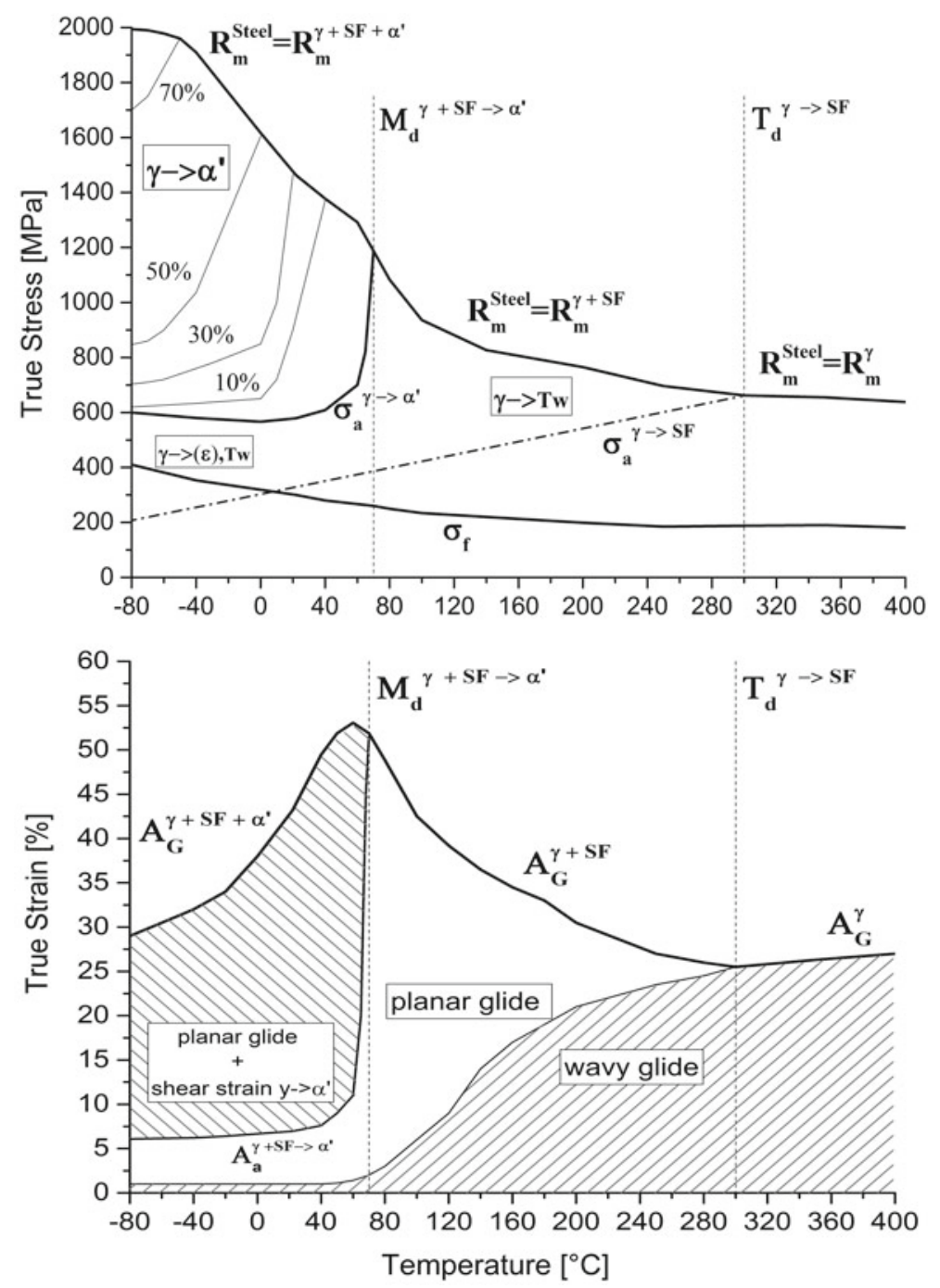

Fig. 20.18 STT and DTT diagrams for the X15CrNiMnN19-4-3 steel

these processes occur depends on the chemical composition. Deformation-induced martensite formation is absent at temperatures above approximately $70{ }^{\circ} \mathrm{C}$, leading to a weak temperature dependence of tensile strength. Upon deformation-induced martensite formation at lower temperatures, the tensile strength increases at a much faster rate. The martensite tends to form within the slip bands in the austenite, thereby restricting dislocations glide within the existing bands. As a result, additional slip bands must be activated to sustain plastic deformation. This explains the high rate 
of strain hardening. In the temperature range between 70 and $-80{ }^{\circ} \mathrm{C}$, the triggering stress for deformation-induced martensite was determined by in situ magnetic measurements to be in the range 600-1180 MPa.

The DTT diagram enables the separation of strain contributions owing to the glide of dislocations in the austenite as well as those due to the deformation-induced twinning and martensitic transformation. The summation of these strain contributions yields the experimental elongation $\left(A_{G}^{\text {Steel }}\right)$ of the steel, which reaches a maximum at $53 \%$ in the studied temperature range of -80 to $400{ }^{\circ} \mathrm{C}$. Since the strain contributions of twinning, $\varepsilon$-martensite formation and dislocation glide are difficult to separate, the DTT diagram in Fig. 20.18 shows only the summation of these contributions.

Due to the high amount of interstitial elements, the X15CrNiMnN19-4-3 has a higher yield strength than the $\mathrm{X} 3 \mathrm{CrMnNi16-7-3/6/9} \mathrm{steels} \mathrm{at} \mathrm{equal} \mathrm{deforma-}$ tion temperatures. Although the martensite content of the X15CrNiMnN19-4-3 at room temperature is significantly lower $(30.3 \mathrm{vol} \%)$ than the martensite content of the X3CrMnNi16-7-3 (82 vol\%), is the yield strength (342-298 MPa) and the ultimate tensile strength $(1663-1198 \mathrm{MPa})$ is higher. The $\mathrm{M}_{\mathrm{d}}$ temperature of the $\mathrm{X} 15 \mathrm{CrNiMnN} 19-4-3$ steel $\left(70^{\circ} \mathrm{C}\right)$ is located between the $\mathrm{X} 3 \mathrm{CrMnNi} 16-7-6\left(100^{\circ} \mathrm{C}\right)$ and $\mathrm{X} 3 \mathrm{CrMnNi} 16-7-9\left(50{ }^{\circ} \mathrm{C}\right)$.

In Fig. 20.19, the Gibbs energy changes for the martensite formation based on the thermodynamic database are compared with the values calculated using the procedure explained in the following and discussed in more detail by Hauser et al. [22]. Whereas the dash-dotted line predicts a continuous increase in the chemical driving force at lower temperatures (down to $-196{ }^{\circ} \mathrm{C}$ ), the chemical driving force

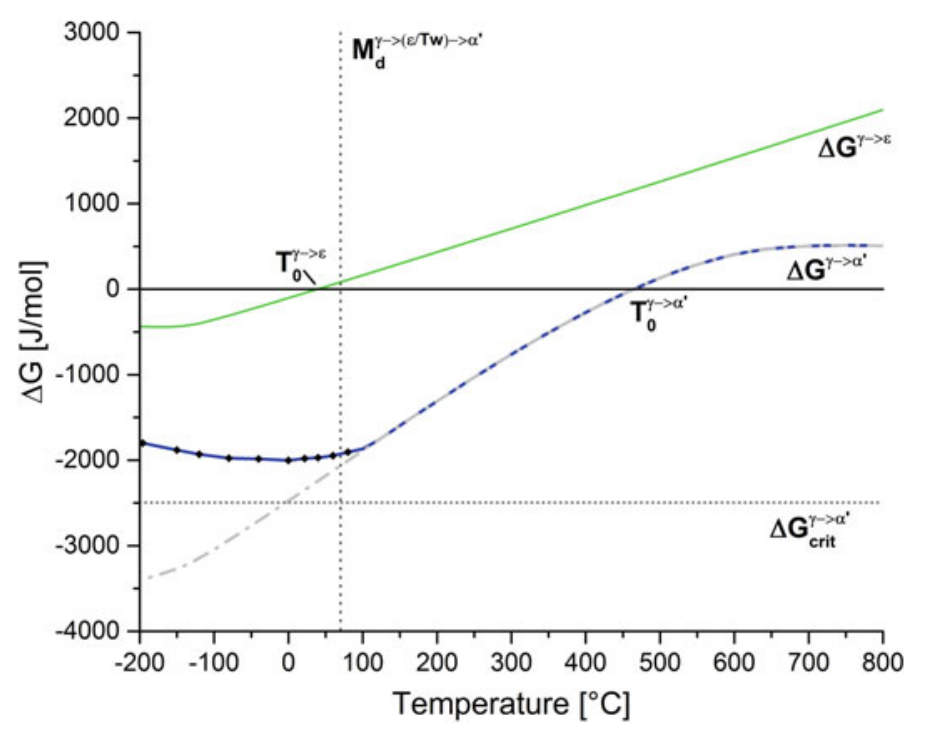

Fig. 20.19 Gibbs energy changes for $\gamma \rightarrow \varepsilon$ and $\gamma \rightarrow \alpha^{\prime}$ phase transformations calculated by Thermo-Calc and corrected Gibbs energy $\gamma \rightarrow \alpha^{\prime}$ with the aid of tensile tests with in situ magnetic measurements for the $\mathrm{X} 15 \mathrm{CrNiMnN19-4-3}$ steel [22] 
based on the revised values remains almost constant below $-80{ }^{\circ} \mathrm{C}$. The observed deviation is most likely caused by changes in the mechanical and physical properties of austenite near the Néel temperature. The critical Gibbs free energies for the formation of martensite at different temperatures were determined by the addition of the chemical and mechanical contributions. The chemical term was obtained from thermodynamic calculations. The mechanical term, on the other hand, was obtained by calculating the mechanical energy supplied to tensile specimens up to the onset of martensitic transformation. The critical driving force for the formation of $\alpha^{\prime}(-2496 \mathrm{~J} / \mathrm{mol})$ was obtained by determining the mechanical energy necessary to trigger the deformation-induced $\alpha^{\prime}$-martensite formation at $0{ }^{\circ} \mathrm{C}$. Driving forces for the formation of $\alpha^{\prime}$-martensite at other tensile test temperatures were then obtained by subtracting the mechanical energies applied to trigger the martensitic transformation from the critical driving force. Additionally, the calculated Gibbs free energy for $\varepsilon$-martensite formation is shown in Fig. 20.19. Due to the low critical driving force of $\varepsilon$-martensite, the $\varepsilon$-martensite formation starts immediately below the $T_{0}^{\gamma \rightarrow \varepsilon}$. Since the $\alpha^{\prime}$-martensite is more stable, the $\varepsilon \rightarrow \alpha^{\prime}$ phase transformation starts at the moment where the critical driving force for $\alpha^{\prime}$ martensite is reached.

\subsection{Conclusions}

The focus of the subproject C3 was the thermodynamic-mechanical modeling of metastable high alloy austenitic CrMnNi steels. To achieve this, several steels were investigated in cooperation with different subprojects of the Collaborative Research Center 799. With the aid of thermodynamic data and flow curve analysis, it is possible to describe the mechanical properties based on the deformation mechanisms and phase transformations. The investigated metastable austenitic steels exhibited the transformation induced plasticity (TRIP) and twinning induced plasticity (TWIP) effects.

First, a new method was developed for the quantitative determination of strength and plastic elongation contributions due to deformation-induced processes during uniaxial tensile loading of austenitic steels. The method was demonstrated using a commercial X5CrNi18-10 steel. For this purpose, the dependence of the overlapping deformation processes in the austenite on the temperature and applied tensile stress was studied in the temperature range of -196 to $40{ }^{\circ} \mathrm{C}$. It was shown that every deformation process leads to a strength and plasticity contribution commensurate with its dominance. The sum of all contributions yielded the tensile strength and the uniform elongation of the steels. Stress-temperature-transformation (STT) and deformation-temperature-transformation (DTT) diagrams were constructed with the aid of flow curve analysis and microstructural examinations. Plastic deformation of martensite was excluded in the developed method. Therefore, the method is only valid for metastable austenitic steels whose initial microstructure is free of as-quenched $\varepsilon$ - or $\alpha^{\prime}$-martensite. 
The influence of the chemical composition on the deformation mechanisms of metastable CrMnNi cast steels was investigated using three high alloy steels, namely X3CrMnNi16-7-3, X3CrMnNi16-7-6 and X3CrMnNi16-7-9. The influence of martensite formation on the mechanical properties of the three steels was studied by tensile tests between -196 and $300{ }^{\circ} \mathrm{C}$. With increasing nickel content, the critical temperatures shifted to lower temperatures. For instance, the $M_{\mathrm{d}}$-temperature decreased from $140{ }^{\circ} \mathrm{C}$ at $3 \% \mathrm{Ni}$ to $50{ }^{\circ} \mathrm{C}$ at $9 \% \mathrm{Ni}$. Furthermore, the increase in the $\mathrm{Ni}$ content was associated with a change in the deformation mechanism at room temperature from a pronounced TRIP effect to a mixture of TRIP and TWIP effects.

A mathematical model was applied to describe the mechanical work due to uniaxial tensile loading. This enabled to determine the critical driving force for the martensitic phase transformation. The deformation-induced formation of $\alpha^{\prime}$-martensite was investigated by tensile testing of X15CrNiMnN19-4-3 cast austenitic steel between -80 and $400{ }^{\circ} \mathrm{C}$. The steel did not exhibit spontaneous $\alpha^{\prime}$-martensite formation at temperatures as low as $-196{ }^{\circ} \mathrm{C}$. The triggering mechanical energies for the deformation-induced $\alpha^{\prime}$-martensite formation were calculated after determining the onset of $\alpha^{\prime}$-martensite formation by in situ magnetic measurements during tensile tests. The results enabled to calculate modified driving forces for the occurrence of the $\gamma \rightarrow \alpha^{\prime}$ phase transformation.

Acknowledgements The authors would like to thank Dr. Alexander Kovalev for the research on the 1st generation steels. Sincere thanks are due to the colleagues at the Institute of Iron and Steel Technology (IEST), Institute of Materials Engineering and the Institute of Materials Science (IWW) for their support and assistance on the experiments: Ms. C. Ullrich and Mr. B. Reichel for the SEM, ECCI and XRD measurements; Dr. T. Kreschel und Mr. G. Franke for the heat treatments; Mrs. G. Schubert for the dilatometry experiments and hardness tests; Mr. P. Neuhold for producing the steels; Dr. R. Eckner and Mr. G. Schade for the tensile tests; Mrs. I. Grahl and Mrs. J. Kreschel for the metallographic sample preparation and light optical microscope observations; Mr. M. Block for the machining of specimens; and all the student assistants for the magnetic measurements. The financial support of the Deutsche Forschungsgemeinschaft (DFG, German Research Foundation) in the framework of Collaborative Research Center 799 (Project number 54473466) subproject C3 was gratefully acknowledged. The authors would also like to thank Prof. P. R. Scheller, the previous director of IEST, for his support on preparing the C3 subproject proposal. Special thanks are extended to all the colleagues from SFB 799 for the valuable and fruitful scientific discussions.

\section{References}

1. R.G. Stringfellow, D.M. Parks, G.B. Olson, Acta Metall. Mater. 40, 1703 (1992)

2. F.D. Fischer, G. Reisner, E. Werner, K. Tanaka, G. Cailletaud, T. Antretter, Int. J. Plast 16, 723 (2000)

3. F. Lecroisey, A. Pineau, Metall. Trans. 3, 391 (1972)

4. S. Martin, S. Wolf, U. Martin, L. Krüger, D. Rafaja, Metall. Mat. Trans. A 47, 49 (2014)

5. S. Wolf, S. Martin, L. Krüger, U. Martin, U. Lorenz, Steel Res. Int. 83, 529 (2012)

6. M. Wendler, B. Reichel, R. Eckner, O. Fabrichnaya, L. Krüger, A. Weiß, J. Mola, Metall. Mater. Trans. A 47, 139 (2016)

7. J.F. Breedis, Acta Metall. 13, 239 (1965) 
8. M. Pozuelo, J.E. Wittig, J.A. Jiménez, G. Frommeyer, Metall. Mater. Trans. A 40, 1826 (2009)

9. R. Rahimi, C. Ullrich, V. Klemm, D. Rafaja, B.C. De Cooman, H. Biermann, J. Mola, Mater. Sci. Eng., A 649, 301 (2016)

10. J. Mola, M. Wendler, A. Weiß, B. Reichel, G. Wolf, B.C. De Cooman, Metall. Mater. Trans. A 46, 1450 (2015)

11. M. Wendler, C. Ullrich, M. Hauser, L. Krüger, O. Volkova, A. Weiß, J. Mola, Acta Mater. 133, 346 (2017)

12. F. Abrassart, Metall. Trans. 4, 2205 (1973)

13. K. Spencer, K.T. Conlon, Y. Bréchet, J.D. Embury, Mater. Sci. Technol. 25, 18 (2009)

14. S. Martin, S. Wolf, U. Martin, L. Krüger, Solid State Phenom. 172-174, 172 (2011)

15. M. Cohen, E.S. Machlin, V.G. Paranjpe, Am. Soc. Metals 242 (1950)

16. L. Kaufman, M. Cohen, Prog. Metal Phys. 7, 165 (1958)

17. G. Ghosh, G.B. Olson, Acta Metall. Mater. 42, 3361 (1994)

18. A. Weiß, H. Gutte, J. Mola, Metall. Mater. Trans. A 47, 112 (2016)

19. A. Kovalev, A. Jahn, A. Weiß, S. Wolf, P.R. Scheller, Steel Res. Int. 83, 576 (2012)

20. A. Kovalev, M. Wendler, A. Jahn, A. Weiß, H. Biermann, Adv. Eng. Mater. 15, 609 (2013)

21. M. Hauser, M. Wendler, S. Ghosh Chowdhury, A. Weiß, J. Mola, Mater. Sci. Technol. 31, 1473 (2015)

22. M. Hauser, M. Wendler, O. Fabrichnaya, O. Volkova, J. Mola, Mater. Sci. Eng., A 675, 415 (2016)

23. M. Hauser, M. Wendler, A. Weiß, O. Volkova, J. Mola, Adv. Eng. Mater. 21, 1800676 (2019)

24. M. Palumbo, Calphad 32, 693 (2008)

25. G. Ghosh, G.B. Olson, J. Phase Equilibria 22, 199 (2001)

26. S.G.T.E. (SGTE), in Ternary Steel Systems: Phase Diagrams and Phase Transition Data, ed. by P. Franke, H.J. Seifert (Springer, Berlin, Heidelberg, 2012), pp. 64-64

27. G.B. Olson, M. Cohen, Metall. Trans. A 7, 1915 (1976)

28. H. Gutte, A. Weiß, Spannungs- und verformungsinduzierte Martensitbildungen in metastabilen austenitischen CrNi-Stählen, Habilitation (TU Bergakademie, Freiberg, 2011)

29. J.R. Patel, M. Cohen, Acta Metall. 1, 531 (1953)

30. H.K.D.H. Bhadeshia, ISIJ Int. 42, 1059 (2002)

31. H. Schumann, Kristallgeometrie - Einfürhung in die Theorie der Gittertransformationen metallischer Werkstoffe, 1st edn. (Deutscher Verlag für Grundstoffindustrie, Leipzig, 1979)

32. H. Ledbetter, M.L. Dunn, Mater. Sci. Eng., A 285, 180 (2000)

33. H. Arslan, H. Arslan, T. Dogan, Phys. Metals Metall. 114 (2013)

34. A. Jahn, A. Kovalev, A. Weiß, S. Wolf, L. Krüger, P.R. Scheller, Steel Res. Int. 82, 39 (2011)

35. A. Kovalev, Thermodynamisch-mechanische Modellierung der verformungsinduzierten $\alpha^{\prime}$-Martensitbildung in austenitischen Cr-Mn-Ni-Stählen, Dissertation (TU Bergakademie Freiberg, 2016)

36. A. Kovalev, A. Jahn, A. Weiß, S. Wolf, P.R. Scheller, Steel Res. Int. 82, 1101 (2011)

37. S. Martin, O. Fabrichnaya, D. Rafaja, Mater. Lett. 159, 484 (2015)

38. R. Rahimi, C. Ullrich, D. Rafaja, H. Biermann, J. Mola, Metall. Mater. Trans. A 47, 2705 (2016)

39. H.-J. Kestenbach, Phil. Mag. 36, 1509 (1977)

40. S. Martin, S. Wolf, S. Decker, L. Krüger, U. Martin, Steel Res. Int. 86, 1187 (2015)

41. S. Martin, C. Ullrich, D. Šimek, U. Martin, D. Rafaja, J. Appl. Cryst. 44, 779 (2011)

42. S. Allain, J.-P. Chateau, O. Bouaziz, S. Migot, N. Guelton, Mater. Sci. Eng., A 387-389, 158 (2004)

43. L. Remy, A. Pineau, Metall. Trans. 5, 963 (1974) 
Open Access This chapter is licensed under the terms of the Creative Commons Attribution 4.0 International License (http://creativecommons.org/licenses/by/4.0/), which permits use, sharing, adaptation, distribution and reproduction in any medium or format, as long as you give appropriate credit to the original author(s) and the source, provide a link to the Creative Commons license and indicate if changes were made.

The images or other third party material in this chapter are included in the chapter's Creative Commons license, unless indicated otherwise in a credit line to the material. If material is not included in the chapter's Creative Commons license and your intended use is not permitted by statutory regulation or exceeds the permitted use, you will need to obtain permission directly from the copyright holder.

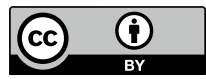

